\title{
ORIGINAL ARTICLE Dedifferentiation into blastomere-like cancer stem cells via formation of polyploid giant cancer cells
}

\author{
N Niu, I Mercado-Uribe and J Liu
}

Our recent perplexing findings that polyploid giant cancer cells (PGCCs) acquired embryonic-like stemness and were capable of tumor initiation raised two important unanswered questions: how do PGCCs acquire such stemness, and to which stage of normal development do PGCCs correspond. Intriguingly, formation of giant cells due to failed mitosis/cytokinesis is common in the blastomere stage of the preimplantation embryo. However, the relationship between PGCCs and giant blastomeres has never been studied. Here, we tracked the fate of single PGCCs following paclitaxel-induced mitotic failure. Morphologically, early spheroids derived from PGCCs were indistinguishable from human embryos at the blastomere, polyploid blastomere, compaction, morula and blastocyst-like stages by light, scanning electron or three-dimensional confocal scanning microscopy. Formation of PGCCs was associated with activation of senescence, while budding of daughter cells was associated with senescence escape. PGCCs showed time- and space-dependent activation of expression of the embryonic stem cell markers OCT4, NANOG, SOX2 and SSEA1 and lacked expression of Xist. PGCCs acquired mesenchymal phenotype and were capable of differentiation into all three germ layers in vitro. The embryonic-like stemness of PGCCs was associated with nuclear accumulation of YAP, a key mediator of the Hippo pathway. Spheroids derived from single PGCCs grew into a wide spectrum of human neoplasms, including germ cell tumors, highgrade and low-grade carcinomas and benign tissues. Daughter cells derived from PGCCs showed attenuated capacity for invasion and increased resistance to paclitaxel. We also observed formation of PGCCs and dedifferentiation in ovarian cancer specimens from patients treated with chemotherapy. Taken together, our findings demonstrate that PGCCs represent somatic equivalents of blastomeres, the most primitive cancer stem cells reported to date. Thus, our studies reveal an evolutionarily conserved archaic embryonic program in somatic cells that can be de-repressed for oncogenesis. Our work offers a new paradigm for cancer origin and disease relapse.

Oncogene (2017) 36, 4887-4900; doi:10.1038/onc.2017.72; published online 24 April 2017

\section{INTRODUCTION}

A hallmark of many malignant tumors is dedifferentiated (immature) cells bearing little or no resemblance to the normal cells from which the cancer originated. ${ }^{1}$ A salient feature of dedifferentiation is the presence of giant cells with multiple copies of genomic DNA, referred to as polyploid giant cancer cells (PGCCs). ${ }^{2}$ A polyploid genome has been found in $37 \%$ of solid tumors. ${ }^{3}$

Polyploid cells were traditionally considered senescent and induction of polyploidy was traditionally considered a tumor suppressor mechanism as polyploid cells are believed to be unable to execute mitosis. ${ }^{4-7}$ However, PGCCs have been shown to generate daughter cells via budding ${ }^{8-12}$ and to contribute to immortalization, transformation and RAS-mediated tumor initiation and metastasis. ${ }^{13-15}$ Furthermore, tetraploid cells, not diploid cells, have been shown to be the main drivers of tumorigenesis. ${ }^{16,17}$ In addition, development of polyploidy has been shown to favor escape from senescence in chemotherapytreated cancer cells. ${ }^{18-20}$ However, the mechanisms by which polyploidy gives rise to malignancy remain poorly defined.

We recently reported that PGCCs are cancer stem cells that can be induced from ovarian cancer cells by the hypoxia-mimetic agent $\mathrm{CoCl}_{2}{ }^{2}$ We showed that PGCCs from ovarian cancer can grow into tumor spheroids, initiate tumor growth in nude mice and differentiate into other benign cell types in vitro and in vivo. ${ }^{2,14,21,22}$ These properties of PGCCs were also reported in colon cancer. ${ }^{23}$ A PGCC phenotype has recently been linked to CSL, a central node in Notch signaling. ${ }^{24}$ We also showed that growth and division of PGCCs involves a multistep programmed process, which we refer as to the giant cell cycle, with four distinct but overlapping phases, initiation, self-renewal, termination and stability, via which PGCCs give rise to new cancer-initiating cells. ${ }^{25}$ However, it is unclear how PGCCs acquire such stemness and which normal developmental stage PGCCs correspond to.

Polyploidy is common in plants and nonvertebrate animals but is generally incompatible with normal development of mammals except in a limited number of somatic cells or tissues., ${ }^{4,26,27}$ Intriguingly, blastomeres, which are produced by cleavage of the zygote in the human preimplantation embryo, frequently display mosaicism of diploidy and polyploidy. As embryogenesis progresses, mononucleated or multinucleated giant blastomeres are commonly seen due to frequent mitosis/cytokinesis failure and endoreplication. ${ }^{28-32}$ The proportion of embryos with more than five polyploid cells is $30.8 \%$ for morulae and $29.3 \%$ for blastocysts. ${ }^{33}$ A large proportion of polyploid blastomeres (50-80\%) display high levels of genomic abnormalities. ${ }^{29-31,34-36}$ Therefore, formation of polyploid blastomeres appears to facilitate the development of compaction and subsequent blastocysts, and 
mitosis/cytokinesis failure may represent a normal mechanism regulating development of the preimplantation embryo. ${ }^{28,29,37}$

The similarities between PGCCs and blastomeres raise the intriguing possibility that PGCCs are somatic equivalents of blastomeres. To investigate this possibility, we tracked the development of single PGCCs derived from ovarian cancer cells treated with paclitaxel.

\section{RESULTS}

PGCCs exhibited a developmental pattern similar to that of the blastomere-like embryo

The experimental design is shown in Figure 1A. Ovarian cancer cell lines Hey, SKOV3 and MDA-HGSC-1 were treated with paclitaxel overnight (16-18 h) to induce mitotic failure. The surviving cells entered an endoreplication cell cycle, grew as PGCCs and were allowed to recover for 7 days as previously described. ${ }^{25}$ At day 7 (spheroid day 1 (sD1)), PGCCs were collected for threedimensional (3D) culture or transferred to stem cell medium and allowed to grow as spheroids. From sD1 to sD21, spheroids were collected at different time points and fixed for immunofluorescence and immunohistochemical staining (IHC). At sD14, spheroids were reattached on cover slides and cultured with differentiation medium for an additional 14 days. At sD28, cell differentiation was evaluated via immunofluorescence and IHC.

At sD1, light microscopy showed that paclitaxel-treated Hey and SKOV3 cells grew as homogeneous PGCCs, and paclitaxel-treated MDA-HGSC-1 cells grew as spheroids with enlarged cells (Supplementary Figure 1A). The percentage of polyploid cells was significantly higher in paclitaxel-treated than in control cells (Supplementary Figure 1B). The percentage of senescent cells was significantly higher in PGCCs than in control cells or PGCCderived daughter cells (Supplementary Figures 1C and D). At sD7, PGCCs showed greater spheroid-forming capacity (Figure 1B) but formed smaller spheroids than control cells (Figure 1C). Representative photos of spheroids are shown in Figure 1D.

To study the development of PGCCs, growth of single control Hey cells and Hey-derived PGCCs in stem cell medium was tracked by light microscopy. Control Hey cells formed coral-like structures within 7-14 days (Figure 1E). Scanning electron microscopy showed long microvilli, ruffles and filopodia on the surface of Hey cells and Hey-derived spheroids (Figure 1F).

In contrast, Hey-derived PGCCs showed vacuolation of the cytoplasm (Figure 1G, white arrow). At sD3 and sD5, daughter cells budded from PGCCs asymmetrically, and at sD7 and sD14, spheroids were observed with mixed giant and small cells (Figure 1G). Nuclei of different sizes were found inside and on the surface of PGCCs (Figure 1H). Similar growth and morphology were seen in MDA-HGSC-derived PGCCs (Supplementary Figure 1E).

To visualize ultrastructural morphology during PGCC growth, we reattached individual Hey-derived PGCCs to ultra-lowattachment plates and tracked PGCC division by scanning electron microscopy. Unexpectedly, when PGCCs started to divide, they were covered by numerous uniform microvilli and were morphologically indistinguishable from blastomeres (Figure 11). ${ }^{38,39}$ The cleavage dividing PGCCs resembled one-cell, two-cell, three-cell, four-cell, six-cell, compaction-like and 10- to 12-cell blastomeres and morulas (Figure 1I), similar to what is observed in the embryoid body. ${ }^{40}$ On 3D confocal scanning microscopy, single PGCCs formed blastocyst-like structures (Figure 1J, Supplementary Movies 1 and 2). 3D confocal scanning images of daughter cells from PGCCs are shown in Supplementary Figure $1 \mathrm{~F}$ and Supplementary Movie 3. We concluded that PGCCs may undergo dedifferentiation toward embryo-like structures.
PGCCs exhibited expression of embryonic stem cell markers

We next performed immunofluorescence staining to determine the expression pattern of four stem cell transcription factors, OCT4, stage-specific embryonic antigen 1 (SSEA1), SOX2 and NANOG, over 14 days in Hey-derived PGCCs transferred to serumfree stem cell medium in ultra-low-attachment dishes on SD1. SSEA1 expression in PGCCs was activated on SD1, limited to the subnuclei or cytoplasm at sD7 and decreased by sD14 (Figure 2a). OCT4 expression was activated on day SD3 and remained activated in a subset of PGCC nuclei at sD14. SOX2 expression and NANOG expression were activated on SD1 and remained activated in a subset of PGCCs at sD14.

Hematoxylin-eosin staining showed that cells in 'spheroids' derived from regular cancer cells (control spheroids) were relatively homogeneous in size (Figure $2 \mathrm{~b}$ ). In contrast, the cells in PGCC-derived spheroids exhibited marked variation in size, and PGCC-derived spheroids had anaplastic nuclei (Figure 2b, black arrows), several cyst-like structures (middle panel) and erythrocyte-like (red arrow) and macrophage-like morphology (blue arrow), suggesting that PGCC-derived spheroids were capable of dedifferentiation in vitro.

Notably, expression of the epithelial marker cytokeratin was significantly lost in PGCC-derived spheroids compared with control spheroids (Figure 2c), whereas expression of the mesenchymal marker fibronectin showed the opposite pattern. Consistent with the immunofluorescence results, strong OCT4 expression was found in rare cells in PGCC-derived spheroids (Figure 2c).

Next, we examined OCT4, NANOG, SOX2 and SOX4 expression in control spheroids and PGCC-derived spheroids from MDAHGSC-1 cells (Figure 2d). Expression of all three factors was increased in PGCCs. Interestingly, the budded daughter cells were also positive for SSEA1 (Figure 2d).

Another recognized feature of embryonic stemness is loss of Xist expression, an RNA marker for inactivation of $\mathrm{X}$ chromosome. ${ }^{41}$ Xist expression was lost in PGCCs derived from Hey and MDA-HGSC-1 cells and was re-acquired by PGCC-derived daughter cells (Figure 2e), further supporting the acquisition of embryonic-like stemness in PGCCs.

At the messenger RNA (mRNA) level, expression of OCT4, NANOG and DAZL (deleted in azoospermia-like), a marker for primordial germ cell development, ${ }^{42}$ increased in paclitaxel-treated Hey and SKOV3 cells in a time-dependent manner (Figure 2f). Western blotting showed that OCT4 and NANOG expression in Hey-derived PGCCs was upregulated from sD1, peaked at sD14, when PGCCs began to bud and had almost disappeared by sD21 (Figure 2g). SOX2 expression in Hey-derived PGCCs was upregulated from sD7, peaked at sD14 and then slightly decreased sD21, when the daughter cells start to appear. Similar patterns of expression were observed in SKOV3-derived PGCCs.

Examination of expression of cancer stem cell markers ALDH1, CD133 and CD117 using fluorescence-activated cell sorting showed that ALDH1-FITC expression was higher in Hey-derived PGCCs than in regular cancer cells (Supplementary Figures 2A and B). No CD133 or CD117 expression was detected in Hey-derived PGCCs or regular cancer cells (Supplementary Figure 2C), suggesting that expression of cancer stem markers is associate with formation of PGCCs.

\section{PGCCs can differentiate into three germ layers in vitro}

To further determine the nature of PGCC-mediated stemness, we examined the phenotype of PGCCs following paclitaxel treatment. The cultures displayed mixtures of PGCCs and budded daughter cells of various morphologies (Figure $3 \mathrm{~A}$ ), including epitheliumlike (Figure $3 A(b)$ ), fibroblast-like (Figure $3 A(c)$ ), mixed epithelial and mesenchymal (Figure $3 A(d)$ ), neuron-like (Figure $3 A(e)$ ) and very small spore-like (yeast-like) cells (Figure $3 A(f)$ ), suggesting that PGCCs are capable of differentiation into multiple lineages of daughter cells. 
A

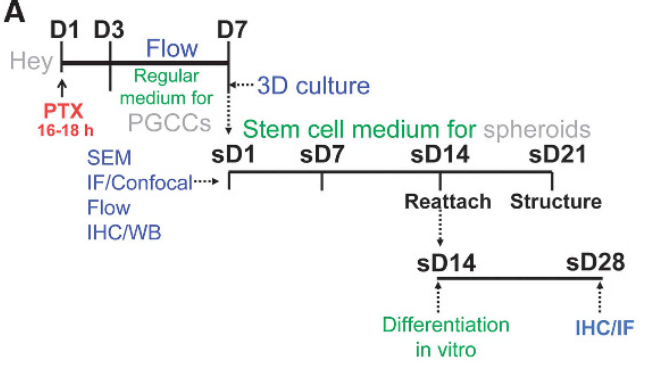

B

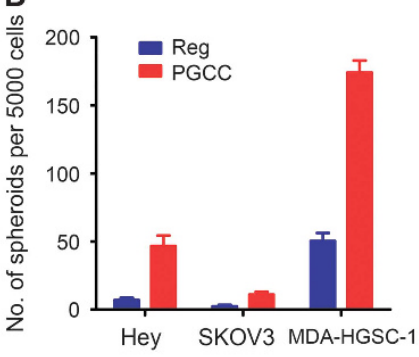

C

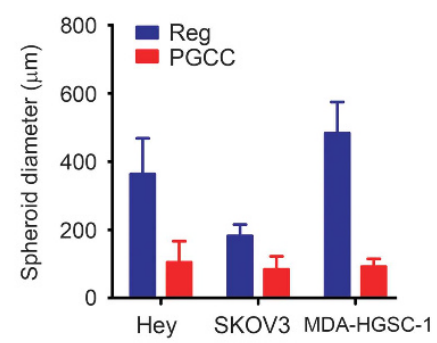

D

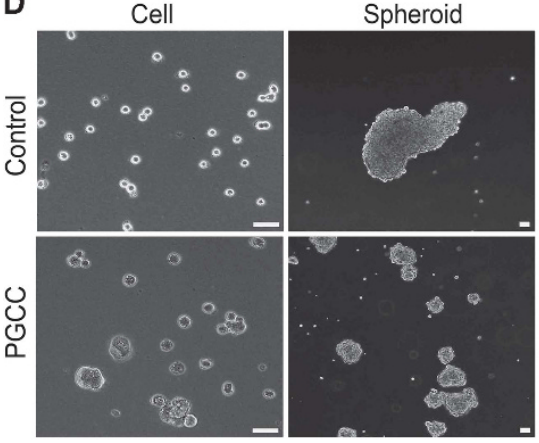

E
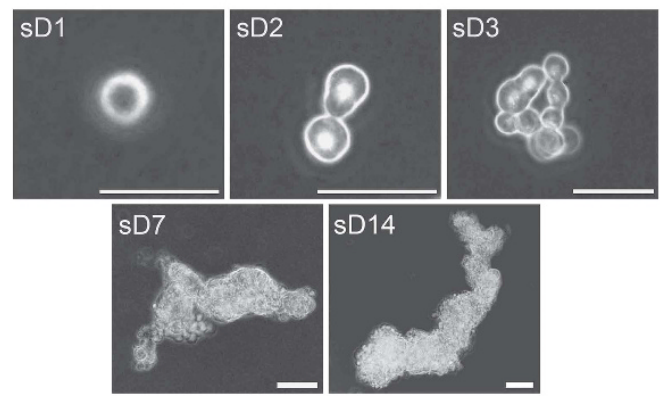

$\mathbf{F}$

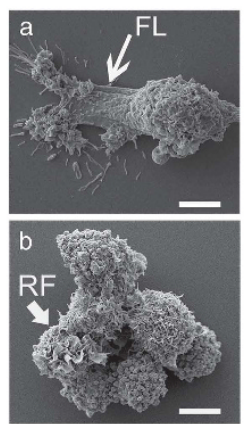

G
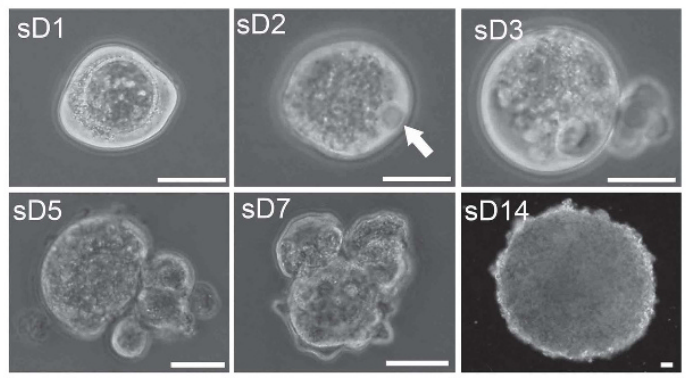

H
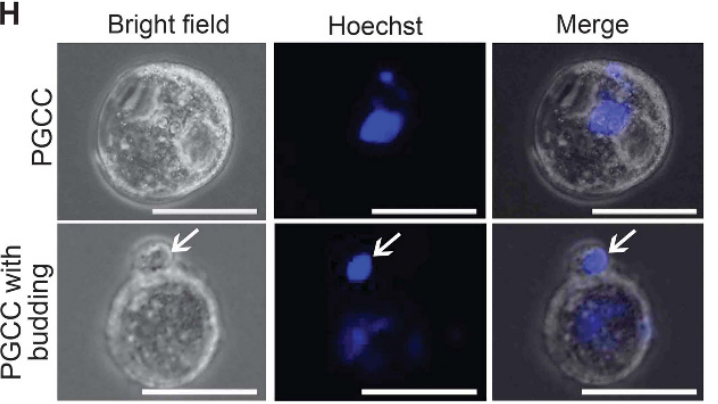

I
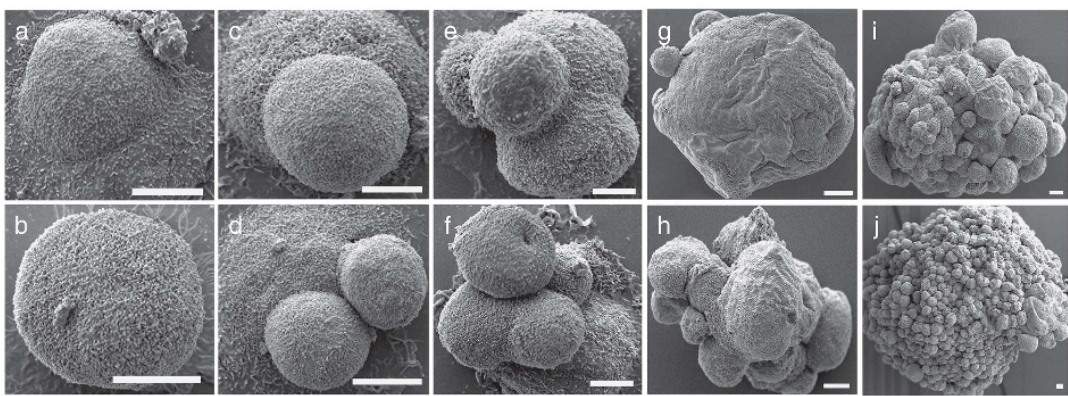

$J$

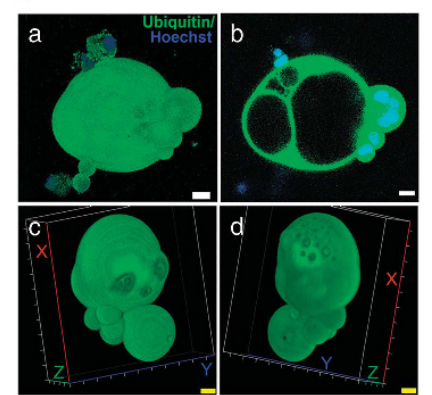

Figure 1. PGCCs exhibited a developmental pattern similar to that of blastomeres. (A) Experimental design. D, day; SEM, scanning electron microscopy; WB, western blotting; IF, immunofluorescence; IHC, immunohistochemistry; $S D$, scanning day. (B) Number (mean \pm s.d.) of regular cancer-cell-derived spheroids and PGCC-derived spheroids per 5000 cells at sD7. Regular cancer-cell-derived spheroids: Hey, $7 \pm 1.7 ;$ SKOV3, $2.3 \pm 1.2$; MDA-HGSC-1, 50.3 \pm 5.9. PGCC-derived spheroids: Hey, $46.7 \pm 7.8$; SKOV3, $11 \pm 2$; MDA-HGSC-1, $174.0 \pm 8.8$. (C) Diameter (mean \pm s.d.) of regular cancer-cell-derived spheroids (Hey, 363.0 \pm 94.5; SKOV3, 182.5 \pm 32.9 ; MDA-HGSC-1, 482.5 \pm 91.5) and PGCC-derived spheroids (Hey, 104.2 \pm 62.0 ; SKOV3, $84.0 \pm 37.0$; MDA-HGSC-1, 92.5 \pm 22.5 ) at SD7. (D) Light microscopic images of control regular Hey cells, Hey-derived PGCCs and resulting spheroids at sD7. Scale bars, $50 \mu \mathrm{m}$. (E) Light microscopic images of 'spheroid' formed from a single regular Hey cell (20 $\mu \mathrm{m}$ in diameter) in serum-free stem cell medium. Scale bars, $50 \mu \mathrm{m}$. (F) Scanning electron microscopy images of regular Hey cell under mitosis (a) and spheroid derived from regular Hey cell (b). FL, filopodium; RF, ruffle. Scale bars, $10 \mu \mathrm{m}$. (G) Light microscopic images of spheroid formation from a single Hey-derived PGCC. Vacuole in the cytoplasm of PGCC is indicated with white arrowhead in panel sD2. The vacuolation is probably due to accumulation of autophagosomes. Scale bars, $50 \mu \mathrm{m}$. (H) Light microscopic nuclear morphology and size of PGCC and PGCC-derived spheroid with budding. Hoechst 33342 stain. Scale bars, $50 \mu \mathrm{m}$. (I) Scanning electron microscopy images of Hey-derived PGCCs. (a and b) PGCC mimicking single polyploid blastomere. (c-j) PGCC cleavage division mimicking blastomere division, including two-cell (c), three-cell (d), four-cell (e), six-cell (f), compaction-like (g), PGCCs with multiple small cleaved daughter cells resembling a morula (h-j). Scale bars, $10 \mu \mathrm{m}$. (J) 3D confocal scanning images of Hey-derived PGCC (a and b) and spheroid derived from Hey-derived PGCC (c and d). $(a$ and $b)$ Blastocyst-like PGCC with budding (a) and cross-sectional view of panel a showing multiple nuclei in a single PGCC (b). Scale bars, $100 \mu \mathrm{m}$. (c and d) front (c) and back (d) views of PGCC-derived spheroid. Scale bars, $10 \mu \mathrm{m}$. 
Next, we investigated the kinetics of activation of expression of alpha fetal protein (AFP), smooth muscle actin (SMA) and $\beta 3$ tubulin (also known as PAX6), markers for endoderm, mesoderm and ectoderm, respectively, in Hey and SKOV3 cells. In Hey cells, mRNA levels of AFP and SMA were increased starting on day 1 of paclitaxel treatment, peaked at day 21 and decreased at day 28, by which time PGCC-derived daughter cells had formed (Figure 3B). In contrast, the mRNA levels of PAX6 remained relatively unchanged over this period. The protein levels of these three markers were much higher in Hey-derived PGCCs than in regular Hey cells and higher in daughter cells than in regular Hey cells (Figure 3C). SMA and $\beta 3$-tubulin protein levels were higher in SKOV3-derived PGCCs than in regular SKOV3 cells and daughter cells (Figure $3 C$ ). However, there was no change in AFP expression at the mRNA or protein level in SKOV3 cells, suggesting that AFP expression may be cell line specific.

We then examined the ability of Hey-derived PGCCs to differentiate. In PGCC-derived spheroids but not in regular Hey cells, oil red staining, a marker of adipose differentiation, was observed when spheroids were cultured in adipogenesis medium (Figure 3D); blue drops indicating sulfate chondroitin, a marker of chondrogenesis, were observed when spheroids were cultured in chondrogenesis medium (Figure 3E); and scale-like osteogeninpositive signals were observed when spheroids were cultured in osteogenesis medium (Figure 3F). Expression of AFP, SMA and $\beta 3$ tubulin was detected when spheroids were cultured in stem cell medium (Figure 3G).

When Hey cells were cultured on a scaffold membrane, PGCCs grew mainly on the membrane surface as normal fallopian-tubelike epithelial cells, the known origin of high-grade serous carcinoma, ${ }^{43}$ whereas regular Hey cells invaded into the membrane (Figure $3 \mathrm{H}$ ). These findings demonstrated that PGCCs were capable of growing back into the normal cell of origin of ovarian cancer.

\section{Differentiation capability of PGCCs depends on nuclear} location of YAP

YAP, a critical Hippo pathway protein, is involved in the regulation of stem cells and cancer development and is responsible for cytokinesis-failure-induced activation of tumor suppressor pathway. ${ }^{44,45}$ We examined the role of YAP in the regulation of stemness and differentiation of PGCCs. YAP was located mainly in the cytoplasm of regular Hey cells and daughter cells but predominantly in the nuclei of PGCCs (Figures $4 a$ and $b$ ). Treatment of PGCCs with dobutamine, which inhibits YAP nuclear translocation, abolished nuclear localization of YAP (Figure 4a). Spheroids formed by Hey-derived PGCCs differentiated into endoderm as indicated by AFP, c-Kit and CXCR4 expression (Figure 4c, upper panels), but dobutamine inhibited this differentiation, as indicated by lack of daughter cells and lack of expression of markers (Figure 4c, lower panels). Spheroids formed by Hey-derived PGCCs also differentiated into astrocyte-like cells as indicated by GFAP expression (Figure $4 d$, upper panels), and again, dobutamine inhibited this differentiation (Figure 4d, lower panels). GATA6, a key regulator in generation of primitive endoderm, ${ }^{46}$ was also activated in PGCCs induced by paclitaxel or $\mathrm{CoCl}_{2}$ (Supplementary Figure 3A), suggesting that GATA6 may be a critical mediator for early embryonic-like development in somatic cells, similar to that in the embryo. We also observed endoderm differentiation of PGCCs induced by $\mathrm{CoCl}_{2}$ (Supplementary Figure 3B).

PGCC-derived spheroids transform into mixed germ cell tumors and carcinoma of different grades in vivo

To determine the nature of tumors that developed from PGCCderived spheroids in vivo, we injected green fluorescence protein (GFP)-ubiquitin-labeled control Hey-cell-derived spheroids (10 000 cells) and PGCC-derived spheroids (1000 cells) collected at sD7 into the subcutis or testis of SCID (severe combined immunodeficiency) mice. All the tested spheroids formed subcutaneous or testis tumors, but PGCC-derived spheroids took significantly longer to form $1 \mathrm{~cm}$ tumors (60-120 days vs 30 days).

Control Hey-cell-derived spheroids formed high-grade carcinomas (Figure 5A(a)). In contrast, PGCC-derived spheroids formed a spectrum of tumors, including mixed germ cell tumor composed of dysgerminoma and embryonic carcinoma (Figures $5 \mathrm{~A}(\mathrm{~b})$ and $\mathrm{A}(\mathrm{c})$ ), dysgerminoma with skeletal muscle differentiation (Figure $5 \mathrm{~A}$ (d)), embryonic carcinoma (Figures $5 \mathrm{~A}(\mathrm{e})$ and $\mathrm{B}(\mathrm{g})$, embryonic carcinoma transitioned into mesenchymal morphology (Figure $5 \mathrm{~A}$ (f)), high-grade carcinoma (Figure 5A(g)), mixed high-grade and lowgrade carcinoma (Figure $5 \mathrm{~A}(\mathrm{~h})$ ) and benign squamous cells (Figure 5A(i)). Mixed germ cell tumors were observed in (19\%) mice with subcutaneous and intratesticular injections (20\%) and no tumors in the control groups $(P<0.0001$; Table 1$)$.

To further determine the level of maturation of germ cells, we performed IHC on continuous sections. Carcinoma from control cells showed high-grade morphology, weak expression of keratin and no expression of germ cell markers SALL4 and OCT4 (Figure 5B). Dysgerminoma and embryonic carcinoma from PGCC-derived spheroids showed SALL4 staining but different levels of epithelial maturation as reflected in different intensities of cytokeratin and OCT4 staining (Figure 5B). Results of additional IHC to characterize the germ cell tumor are shown in Supplementary Figures $4 \mathrm{~A}$ and $\mathrm{B}$. We also demonstrated that germ cell tumors were derived from human, not mice, using GFPubiquitin-labeled cancer cells (Supplementary Figure 4C).

The above findings suggested that PGCCs were capable of differentiation into primordial germ cells and a wide spectrum of epithelial neoplasms from high-grade to benign tumors.

PGCC-derived daughter cells acquire drug resistance and mesenchymal features

To determine whether PGCC-derived daughter cells differ from parental regular cancer cells, we first analyzed the apoptotic response and sensitivity to paclitaxel. Untreated daughter cells had more polyploid cells than regular cells did (Figure 6a). Following paclitaxel treatment, the total apoptotic percentage (Q2 + Q4) was lower in daughter cells than regular cells (Figure 6b). The IC50 values for paclitaxel and vincristine were significantly higher for daughter cells than for regular cells, but the IC50 values for olaparib and topotecan did not differ between the two cell types (Figure 6c, Supplementary Table 2), demonstrating that paclitaxelinduced PGCCs can generate daughter cells chemoresistant not only to paclitaxel but also to other drugs.

The daughter cells were less invasive than the regular cancer cells (Figures $6 \mathrm{~d}$ and e). Both PGCCs and daughter cells displayed increased expression of pan-cytokeratin, mesenchymal markers vimentin, fibronectin and $\mathrm{N}$-cadherin, and epithelial-mesenchymal transition regulatory transcription factors Snail, Slug and Twist 2 and decreased expression of $\beta$-catenin (Figure $6 f$ ). Morphologic features of epithelial-mesenchymal transition were also observed in xenografts (Figure $6 \mathrm{~g}$ ). Tumors from regular cancer cells grew faster than tumors from PGCC-derived daughter cells (Figure $6 \mathrm{~g}$ ). The regular cancer-cell-derived tumors had predominantly epithelial cell morphology, whereas the daughter-cell-derived tumors had mesenchymal-shaped cells with increased heterogeneity (Figure 6g), suggesting that decreased proliferation together with acquired ability to differentiate via epithelial-mesenchymal transition confers acquired resistance to paclitaxel in daughter cells. 
Formation of PGCCs and dedifferentiation of ovarian cancer after chemotherapy

We reasoned that we should be able to observe dedifferentiation following chemotherapy in ovarian cancers in patients. Toward this end, we examined paired specimens of human ovarian cancer obtained before and after chemotherapy. Although the prechemotherapy specimens had relatively homogeneous cells, the post-chemotherapy specimens had increased numbers of a

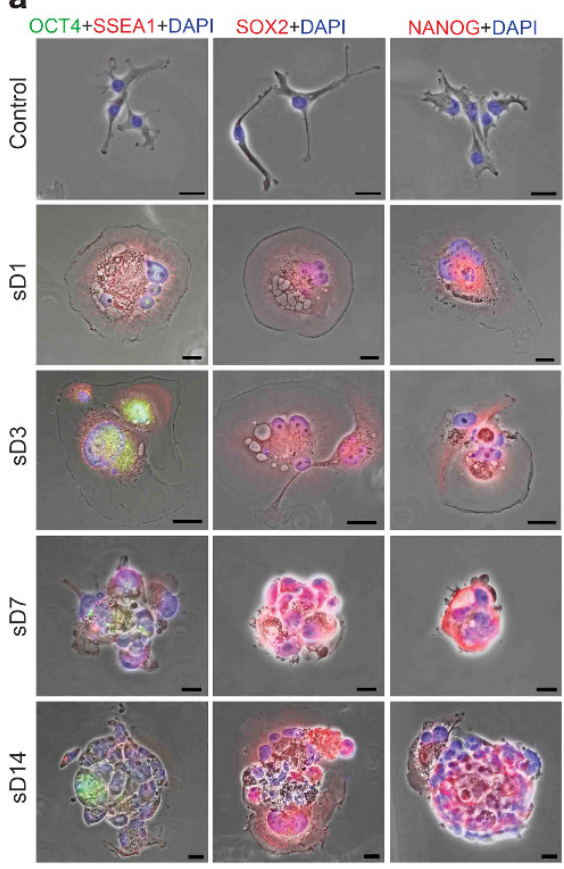

b

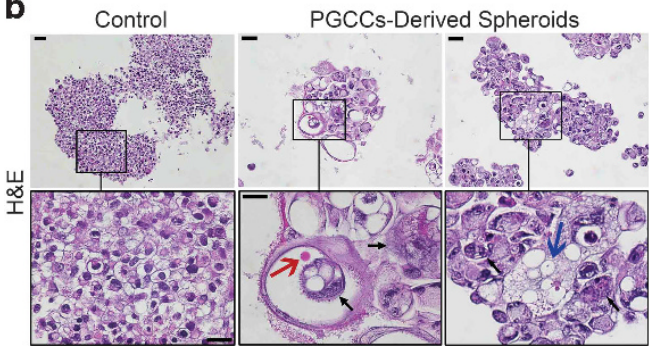

C

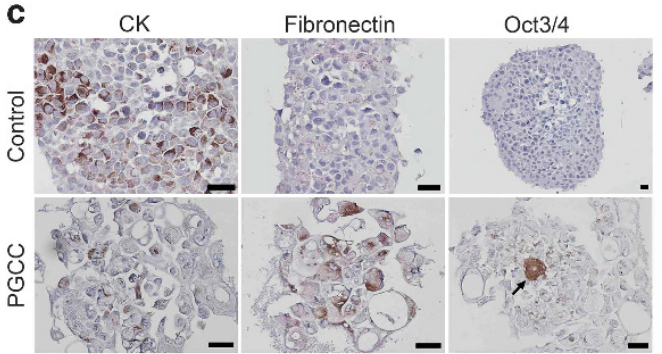

d
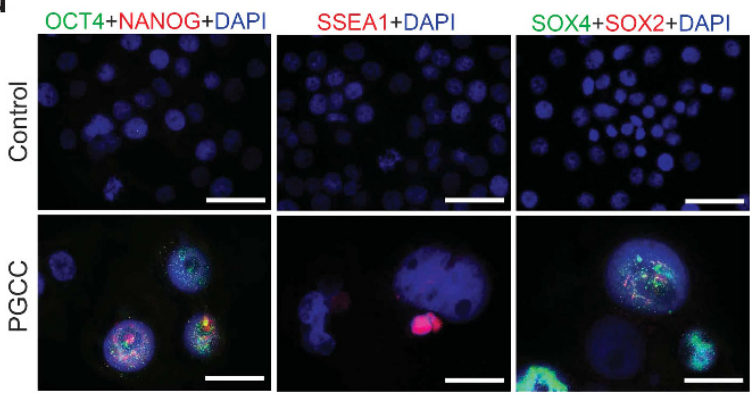

e

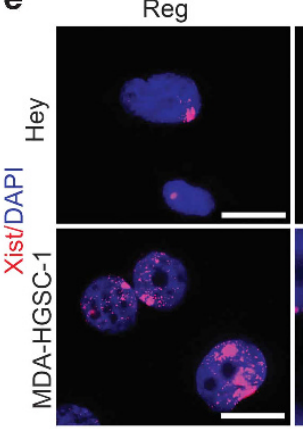

PGCC

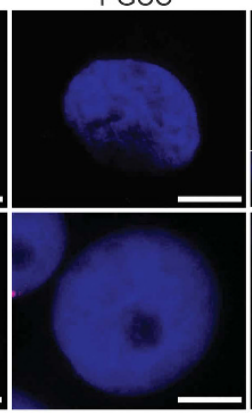

Daughter cells

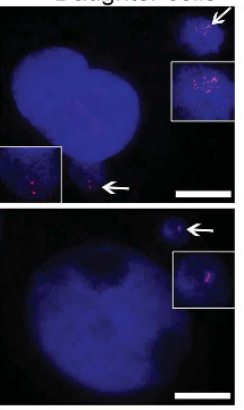

'
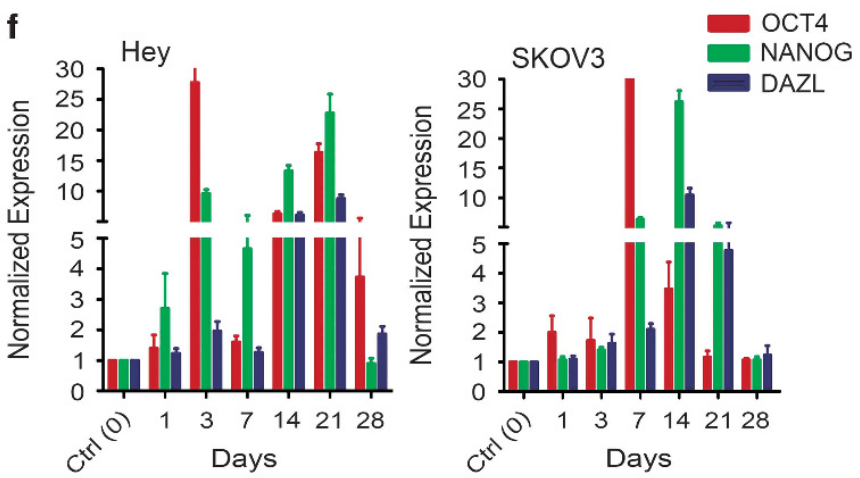

g

Hey

SKOV3

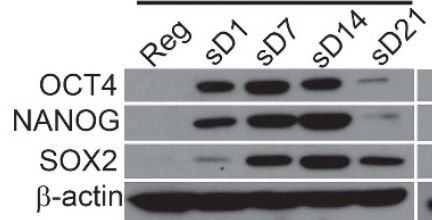

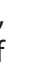


A
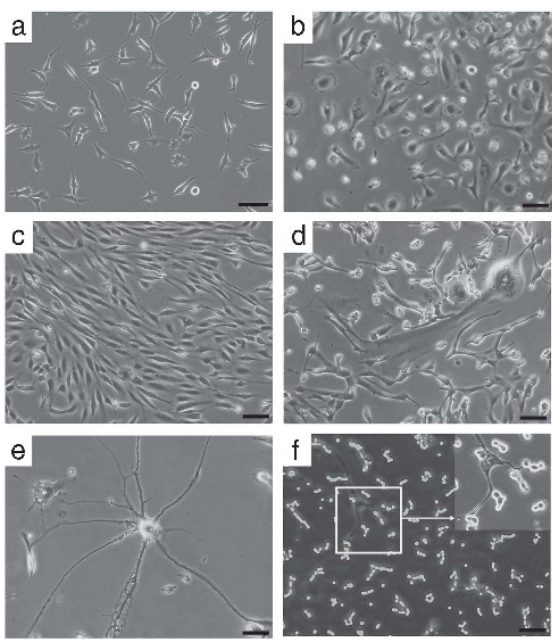

D

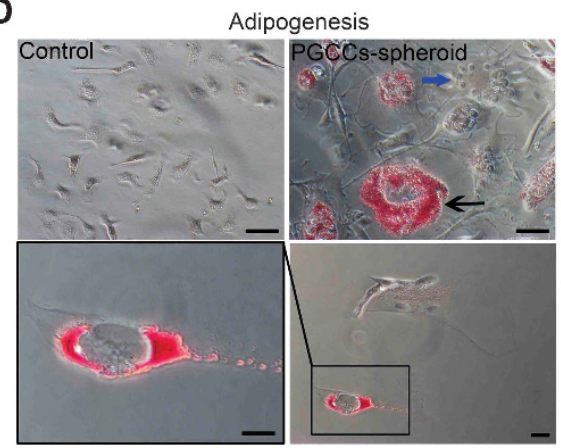

G

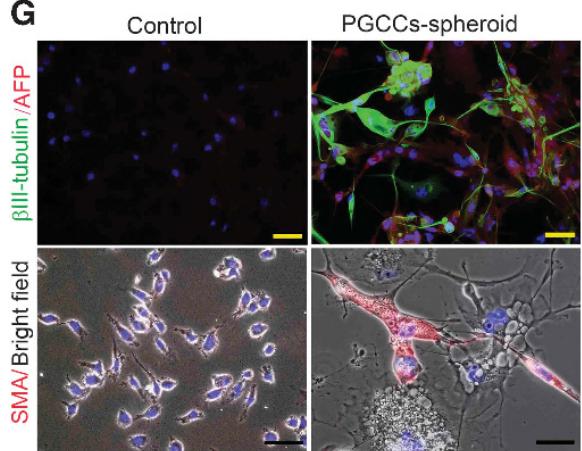

B
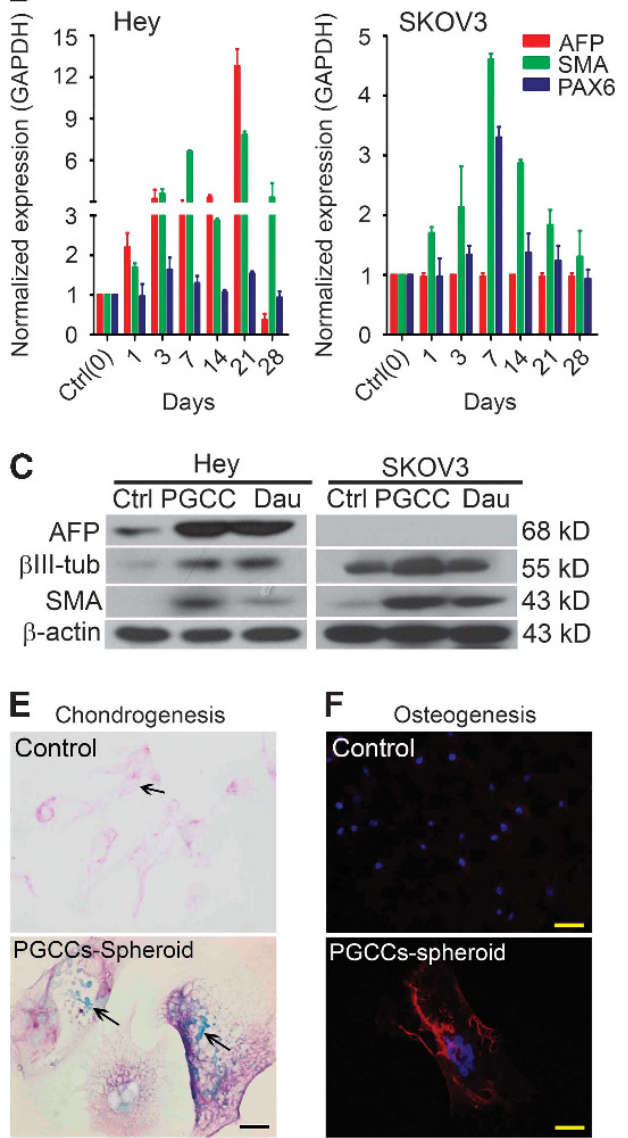

$\mathbf{H}$

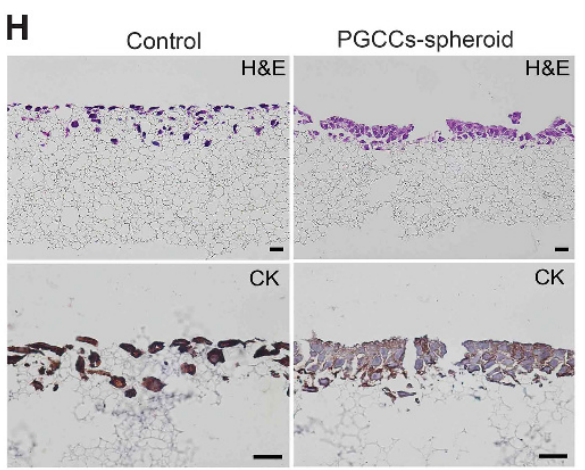

Figure 3. Differentiation of PGCCs in vitro. (A) Differentiation of PGCC to cells of different morphology at 2 months of culture in regular medium. (a) Regular Hey cells. (b-f) Daughter cells of different morphology, including epithelium-like (b), fibroblast-like (c), mixed epithelial and mesenchymal cells (d), neuron-like (e) and small spore-like cells (f). (B) Normalized mRNA expression of proteins associated with three germ layers in Hey-derived and SKOV3-derived PGCCs over 28 days of recovery in regular medium. AFP, SMA and PAX6 are markers for endoderm, mesoderm and ectoderm, respectively. (C) Expression of proteins associated with three germ layers in regular Hey and SKOV3 cells, PGCCs derived from these cells and PGCC-derived daughter cells. AFP, SMA and $\beta 3$-tubulin are markers for endoderm, mesoderm and ectoderm, respectively. Ctrl, regular cancer cell (day 0); PG, PGCC at sD1; Dau, daughter cell. (D-F) Adipocyte (D), chondrocyte (E) and osteocyte (F) differentiation of regular Hey cells and reattached spheroids derived from PGCCs cultured in specific differentiation medium for 14 days. Black arrow in $\mathbf{D}$, oil red-positive vesicle. Blue arrow in $\mathbf{D}$, negative cell (internal reference). Black arrows in $\mathbf{E}$, blue signals of sulfate chondroitin. (G) Immunofluorescence images of three-germ-layer differentiation of regular Hey cells and reattached spheroids from PGCCs. (H) 3D culture of regular Hey cells and PGCCs (at sD1) in the Alvetex scaffold system for 7 days. Regular Hey cells penetrated into the scaffold membrane, while PGCCs mainly grew on the surface of the membrane and formed a monolayer epithelial-like structure (hematoxylin-eosin (H\&E) staining). Human-specific cytokeratin (CK) positivity confirmed the epithelium source.

anaplastic PGCCs with marked variation in size and large bizarre nuclei (Figures 7A and B). Post-chemotherapy specimens had small daughter cells budded off from a single PGCC (Figures 7B and $C$, black arrow) and erythrocyte-like cells within the cytoplasm of PGCCs (Figures 7Bd, blue arrow). The nuclear area of budded daughter cells was significantly smaller than that of prechemotherapy cancer cells (Figure 7D).

After chemotherapy, 3 of 38 samples were positive for OCT4 (in cytoplasm and nuclei), 12 of 38 were positive for NANOG (mainly in cytoplasm) and 17 of 38 were positive for SOX2 (mainly in 

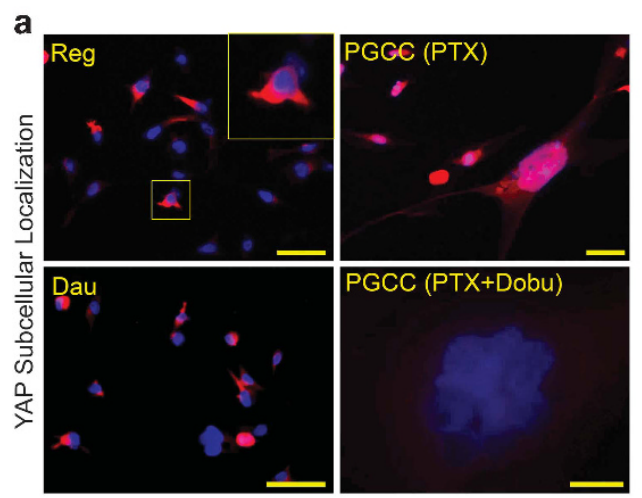

c
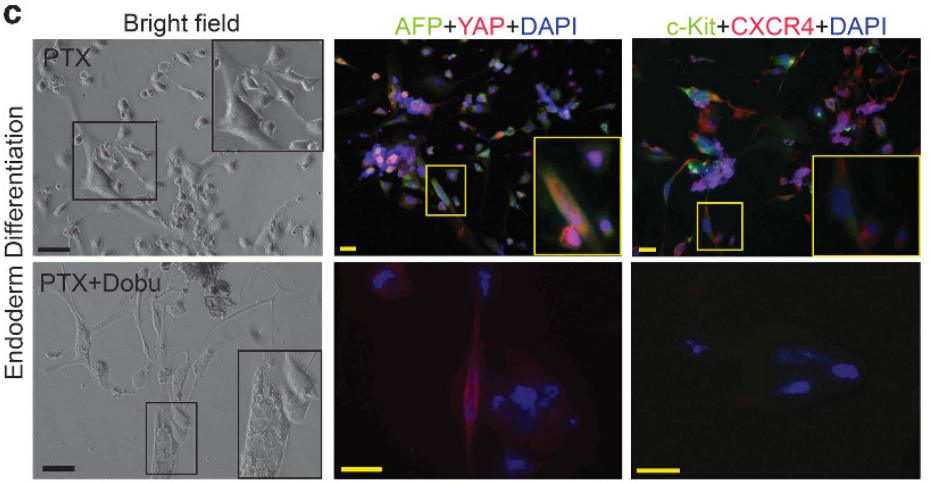

d

Bright field
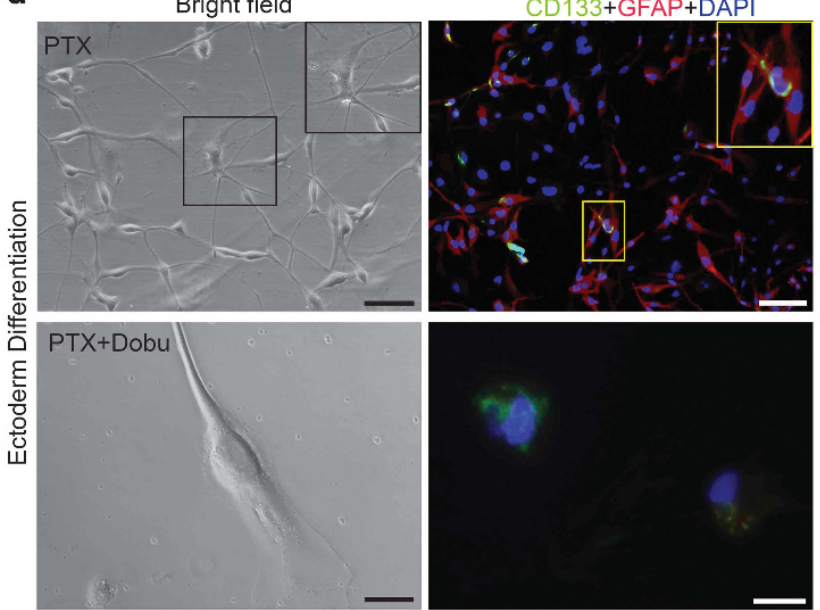

Figure 4. Subcellular localization of YAP and differentiation of PGCCs to endoderm and ectoderm (astrocytes). (a) Expression and distribution of YAP in test cells. In regular cells and PGCC-derived daughter cells, YAP was mainly located in the cytoplasm, but in PGCCs, YAP was predominantly located in the nucleus. Translocation of YAP to the nucleus in PGCCs could be inhibited by dobutamine (Dobu), leading to continued endoreplication and budding failure and death. (b) Proportion of YAP in nucleus in regular cells, PGCCs and PGCC-derived daughter cells. The proportion of YAP in the nucleus was significantly higher in PGCCs (Hey, 73.0 $\pm 3.0 \%$; SKOV3, 72.6 $\pm 0.6 \%$ ) and daughter cells (Hey, $9.7 \pm 0.6 \%$; SKOV3, $8.6 \pm 0.6 \%$ ) than in regular cells (Hey, $0.7 \pm 0.5 \%$; SKOV3, $0.4 \pm 0.5 \%$ ). (c and d) Endoderm differentiation (marked by AFP, c-Kit and CXCR4) and astrocyte differentiation (marked by GFAP and CD133) were inhibited by dobutamine (Dobu). Scale bars, $50 \mu \mathrm{m}$.

nuclei); before chemotherapy, no cases were positive for OCT4 or NANOG, and only 2 of 38 were positive for SOX2 (mainly in the cytoplasm; Figure 7E). Nuclear localization of YAP was observed in the three cases of post-chemotherapy not in pre-chemotherapy control (Figure 7E). These findings demonstrated that treated cancer cells showed increased expression of embryonic stem cell markers in a subset of post-chemotherapy treated ovarian cancers.

Xist expression is generally associated with differentiated state of somatic cells. ${ }^{41}$ We examined Xist expression in regular cancer cells and PGCCs. Xist was strongly expressed in nuclei of cancer and stromal cells before chemotherapy but was largely lost in nuclei of PGCCs after chemotherapy (Figure 7F), further supporting the concept that PGCCs acquired embryonic-like stemness.

\section{DISCUSSION}

In this work, we demonstrated that PGCCs are the somatic equivalent of blastomeres. This study validated our early reports that showed embryonic-like stemness of PGCCs. ${ }^{2,14,21,22}$ By using $\mathrm{CoCl}_{2}$ to induce hypoxia or paclitaxel to induce mitotic failure, we 


\section{A}
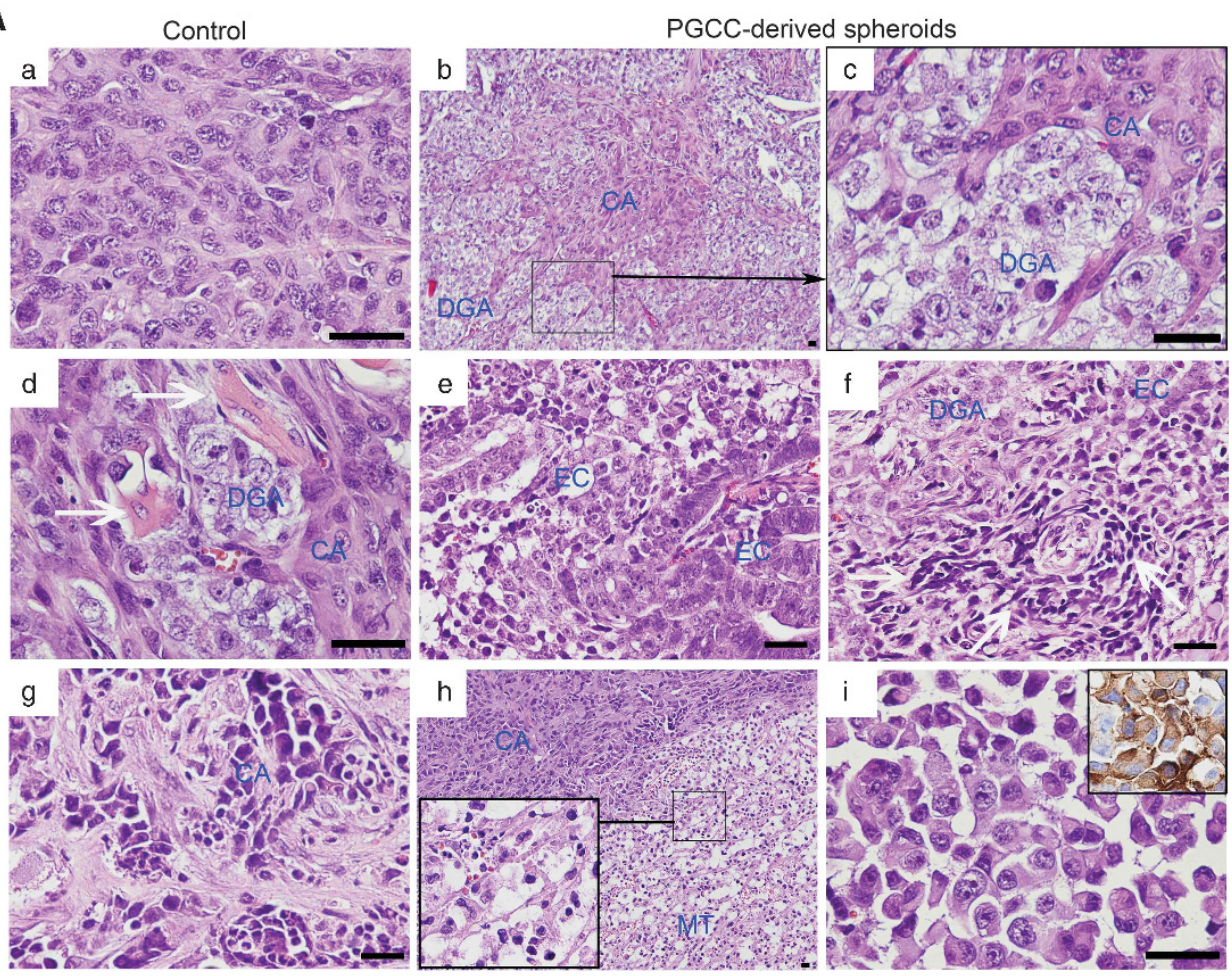

B
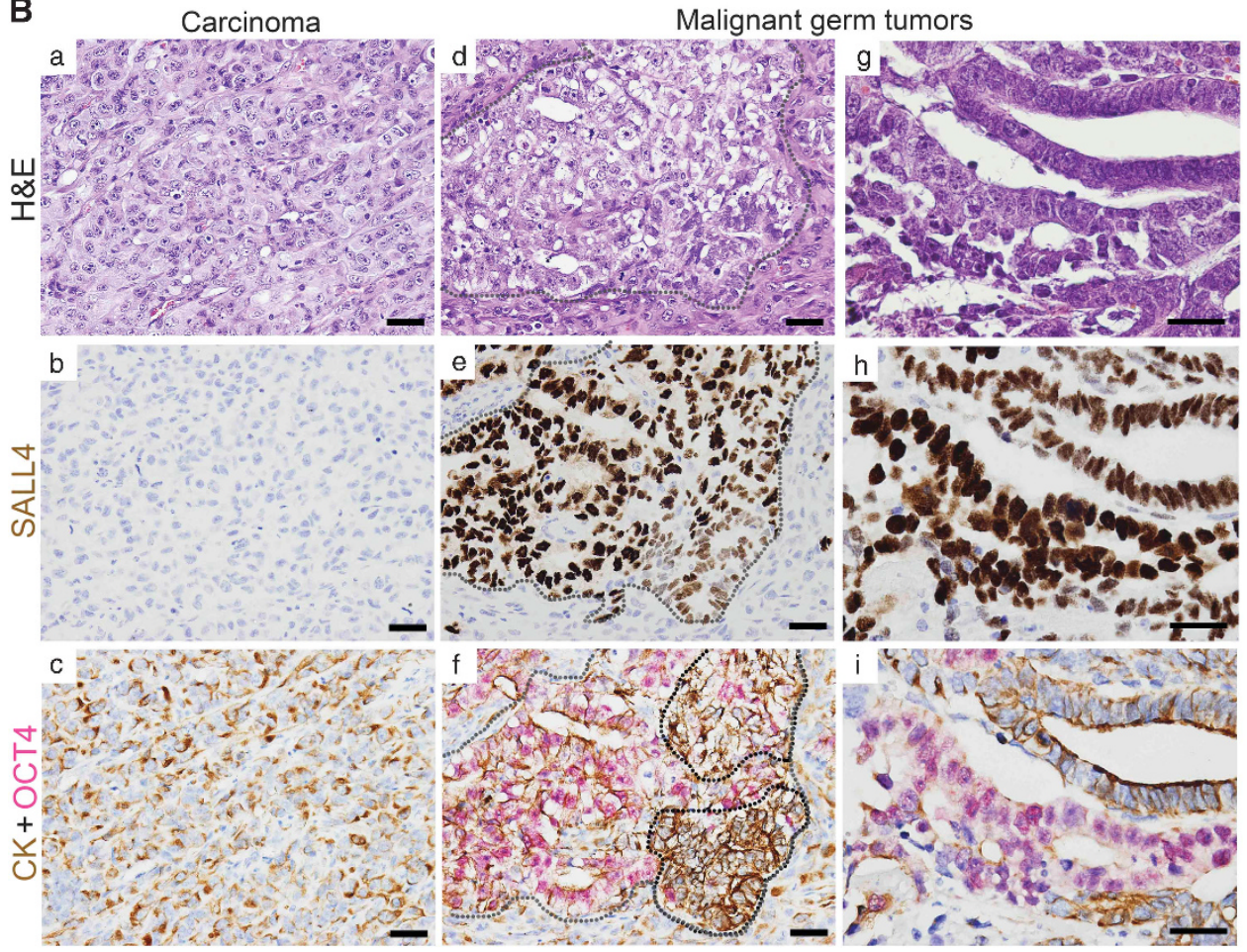

Figure 5. Formation of germ cell tumors and carcinomas of different grades from PGCC-derived spheroids. (A) Hematoxylin-eosin (H\&E)stained images from xenografts formed by control Hey cells and PGCC-derived spheroids. (a) control Hey cells; (b) low-power view of multiple foci of dysgerminoma in a background of carcinoma; (c) high-power view of dysgerminoma showing vesicular nuclei and clear cytoplasm of tumor cells characteristic of primordial germ cells; (d) dysgerminoma with skeletal muscle differentiation; (e) mixed dysgerminoma and embryonic carcinoma; (f) dysgerminoma with mesenchymal morphology; (g) high-grade carcinoma; (h) mixed high- and low-grade tumor with high-power view; (i) benign squamous cells with immunohistochemical staining against cytokeratin. (B) H\&E staining and IHC for SALL4, cytokeratin (CK) and OCT4 on continuous sections of xenografts formed by regular Hey cells (Control) and malignant germ cell tumors generated from spheroids derived from PGCCs. In control xenografts formed by regular Hey cells, cancer cells were positive for human-specific CK, but not for OCT4 and SALL4. In xenografts formed by PGCC-derived spheroids, all of the cancer cells were positive for human-specific CK, and there were clusters of cells positive for OCT4 and SALL4. Gray circles show the same subpopulations. Black cycle indicates cytokeratin positive cells. Scale bars, $50 \mu \mathrm{m}$. 
Table 1. Frequency of tumors with different levels of differentiation in the developmental hierarchy within the xenografts inoculated with PGCCderived spheroids in SCID mice

\begin{tabular}{llcc}
\hline Group & Diagnosis & Injection site & \\
\cline { 3 - 4 } & & Subcutaneous (percentage) & Testis (percentage) \\
\hline Control & Mixed germ cell tumor & $0(0)$ & $0(0)$ \\
& High-grade carcinoma & $8(100)$ & $8(100)$ \\
PGCCs & Mixed germ cell tumor & $3(19.0)$ & $2(20.0)$ \\
& Carcinoma & $13(81.0)$ & $8(80.0)$ \\
& High grade & $8(50)$ & $5(50.0)$ \\
& Low grade & $0(0)$ & $0(0)$ \\
\hline Abbreviations: PGCC, polyploid giant cancer cell; SCID, severe combined immunodeficiency. & $3(30.0)$ \\
\hline
\end{tabular}

showed that PGCCs acquired the properties of blastomeres, including differentiation into three germ layers and formation of germ cell tumors and carcinoma of different grades as well as benign tissue, similar to what have traditionally been referred as teratocarcinomas except that the tumors described here were generated via reprogramming from epithelial carcinoma cells. ${ }^{47,48}$ To our knowledge, PGCCs are the most primitive induced cancer stem cells reported to date.

The embryonic origin of cancer was proposed as early as the late nineteenth century by Cohnheim in $1867 .{ }^{49}$ However, direct experimental evidence for an embryonic origin of cancer was lacking until Stevens demonstrated in 1964 that the embryonic stem cells from murine blastocysts could develop into teratoma/ teratocarcinoma; ${ }^{50,51}$ and Pierce demonstrated in the same year that single embryonic carcinoma cells could generate multiple lineages of benign cells $s^{52}$ and in 1971 that carcinoma can generate benign cells. ${ }^{53}$ This work led Pierce to propose that tumors are caricatures of the process of tissue renewal and maturation arrest. ${ }^{5,55}$ These early experiments clearly linked embryogenesis, tissue differentiation and tumor initiation.

More recently, the work of Nobel laureates Gurdon and Yamanaca and others has made clear that much development is a bidirectional process. ${ }^{56-58}$ The tumorigenicity of both embryonic stem cells and induced pluripotent stem cells is well known. ${ }^{59,60}$ Just as maturation arrest of differentiation can lead to tumor development, incomplete reprogramming can lead to tumor development, ${ }^{61}$ activation of embryonic program has also been shown in irradiation treated tumor cells. ${ }^{62}$ although it remains unknown whether there is an endogenous pathway capable of activating an embryonic program in somatic cells. Our findings reported here demonstrate that PGCCs may be a missing link that can lead to de-repression of a repressed embryonic program in somatic cancer cells for drug resistance and disease relapse.

Our findings above and in our previous publications ${ }^{2,21,22,25}$ prompted us to conceptualize a blastomere model for tumorigenesis and disease relapse. In normal preimplantation embryonic development (Figure 8A), after fertilization, the zygote undergoes cleavage division to generate a two- and four-cell blastomere, which can grow into polyploid blastomeres because of increased mitosis/cytokinesis failure, which undergo compaction and then develop into a morula and blastocyst. Differentiation into the inner cell mass and trophectoderm then occurs, followed by cell sorting into the primitive endoderm and pluripotent epiblasts and then gastrulation to form the three germ layers and germ cells. The stem cells differentiate along specific levels of the developmental hierarchy and become restricted to specific cell types. Maturation arrest due to genetic/epigenetic mutations acquired in embryo or later in life ( $M$ ' for germ cells; M1 to M4 for somatic cells) at the different levels of the developmental hierarchy generates tumors of different grades of malignancy, a phenomenon referred to as Pierce maturation arrest. ${ }^{55}$

Similarly, somatic cells can enter blastomere-like development by switching mitosis to endoreplication (Figure $8 \mathrm{~B}$ ) via the giant cell cycle that we recently described. ${ }^{25}$ During the initiation phase of the giant cell cycle, failed mitosis/cytokinesis activates endoreplication, by which cells can escape senescence/apoptosis. During the self-renewal phase, the polyploid cells grow autonomously and develop into compaction-, morula- and blastocyst-like embryos and generate inner cell-mass-like stem cells. During the termination phase, polyploid growth ends and the inner cell-masslike stem cells bud small embryonic-like stem cells. During the stability phase, these stem cells with acquired genetic/epigenetic mutations that arrested at different developmental hierarchies (a', b', c' and d') will gradually acquire competence in mitosis, achieve stable diploid karyotype and grow into tumors of different grades, including germ cell tumors. The level of dedifferentiation varies according to the type of stressors and duration of stress and the cell type: the longer the giant cell cycle, the closer the resulting cells to the primitive stage and the greater level of their developmental potential for different grades as well as types of tumors.

Our findings also provide new insights into chemotherapy resistance. Paclitaxel is a microtubule poison; ${ }^{63}$ its therapeutic effects are largely due to arrest of cells at mitosis, which leads to mitotic catastrophe and cancer cell death via apoptosis or necrosis or chromosomal missegregation. ${ }^{64,65}$ However, resistance to paclitaxel is common in patients. Polyploidy has recently been proposed to be the main cause of docetaxel resistance. ${ }^{66}$ Our studies provide strong experimental evidence supporting a central role of polyploidy in drug resistance by providing most primitive cancer stem cells for drug resistance and disease relapse.

In summary, our findings constitute strong experimental evidence that PGCCs function as blastomere-like stem cells to facilitate the neoplastic evolution in response to various genetic/ epigenetic or environmental stressors. Blocking formation of polyploidy and redirecting differentiation of PGCCs toward benign lineages may be promising therapeutic approaches for cancer.

\section{MATERIALS AND METHODS}

Cell lines, cell labeling, PGCC formation and clinical specimens Human ovarian cancer cell lines Hey and SKOV3 were recently described. ${ }^{25}$ MDA-HGSC-1, MD Anderson high-grade serous carcinoma cell line 1 (ID 2414), was established from a patient-derived xenograft from high-grade ovarian serous carcinoma. This line grew as spheroids in low-attachment dishes in modified medium (WIT/NoE, 1:1). The Hey cells were labeled with ubiquitin-enhanced GFP (FG12) as described previously. ${ }^{25}$ At $60-70 \%$ 
a

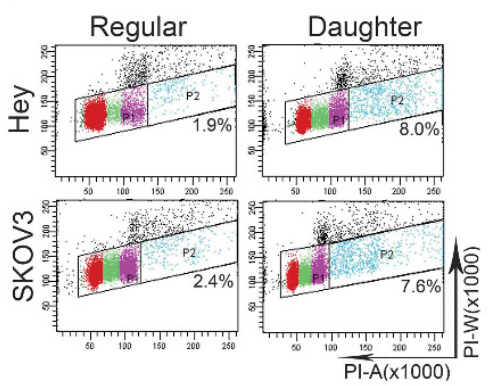

b

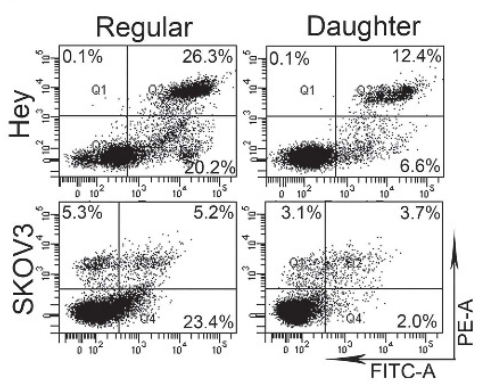

c

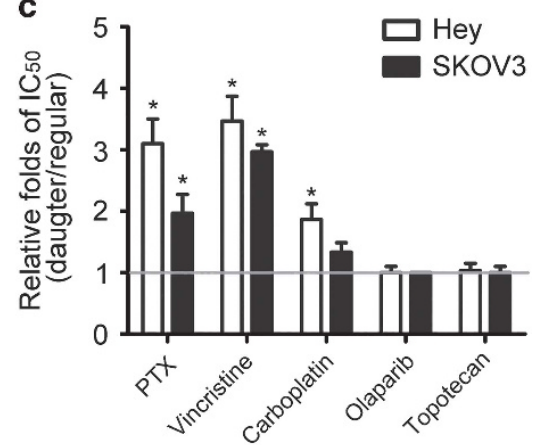

d

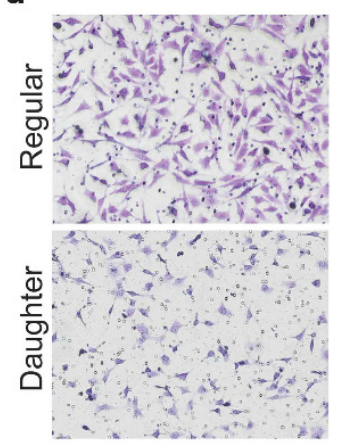

e

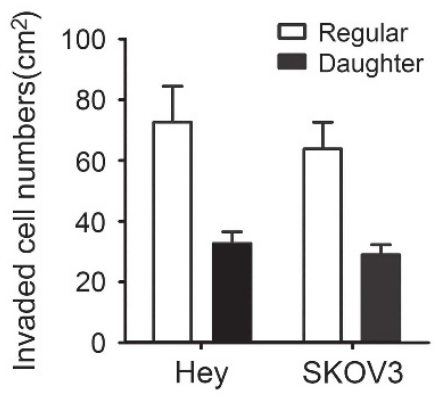

f

\section{$\frac{\text { Hey }}{\text { Reg PG Dau }} \frac{\text { SKOV3 }}{\text { Reg PG Dau }}$}

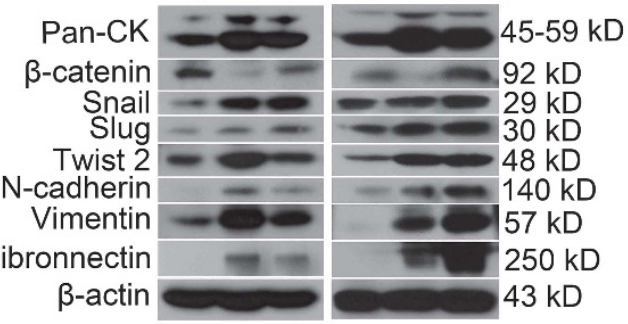

g

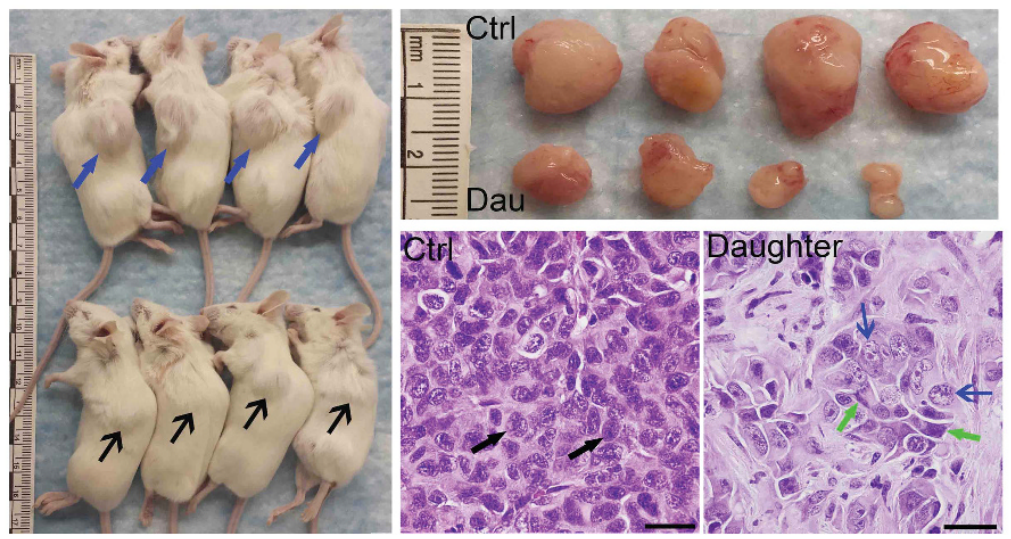

Figure 6. Acquisition of drug resistance and increased expression of epithelial and mesenchymal markers in PGCC-derived daughter cells. (a) Percentage of polyploid cells (blue dots in gate P2) among regular Hey and SKOV3 cells and PGCC-derived daughter cells. (b) Percentage of apoptotic cells (Q2+Q4) among regular Hey and SKOV3 cells and PGCC-derived daughter cells after exposure to 100 nM PTX and recovery for 48 h. (c) Sensitivity of PGCC-derived daughter cells compared with corresponding regular cancer cells to PTX, vincristine, carboplatin, olaparib and topotecan ( $24 \mathrm{~h}$ treatment). Results are presented as the ratio of the IC50 value for daughter cells to the IC50 value for regular cancer cells. The IC50 values are indicated in Supplementary Table 2. (d and e) Invasion ability of regular Hey and SKOV3 cells and PGCC-derived daughter cells. In matrigel-transwell invading experiments, the number of invaded regular Hey cells $\left(72.6 \pm 11.8 / \mathrm{cm}^{2}\right)$ and SKOV3 cells $\left(63.8 \pm 8.7 / \mathrm{cm}^{2}\right)$ was higher than the number of invaded daughter cells (Hey daughter, $32.7 \pm 3.8 / \mathrm{cm}^{2} ;$ SKOV3 daughter, $\left.28.6 \pm 3.4 / \mathrm{cm}^{2}\right)$. $(\mathrm{f}$ ) Expression of epithelium-related and mesenchyme-related protein in tested cell lines, detected by western blotting. Reg, regular cancer cells; PG, PGCCs at day 7 after paclitaxel treatment; Dau, daughter cells. (g) Acquisition of mesenchymal phenotype in xenografts generated by PGCCderived daughter cells. Left panel, tumor nodules of regular control and daughter cell groups are indicated with blue and black arrows, respectively. Right upper panel, nodule size of test groups. Right lower panels, H\&E staining of xenografts. Similar-sized cancer cells in control are indicated with black arrows, and heterogeneous-size cancer cells in the daughter group are indicated with blue (epithelial-like) and green (mesenchymal-like) arrows.

confluence, the cells were treated with paclitaxel (500 nm, Sigma, St Louis, MO, USA) overnight (16-18 h); the cells were then allowed to recover for 7 days to form PGCCs.

Thirty-eight paired samples of archived, paraffin-embedded high-grade ovarian serous carcinoma obtained before and after six cycles of paclitaxeland carboplatin-based chemotherapy were subjected to histology analysis and IHC for different markers. Use of these samples was approved by MD Anderson's Institutional Review Board.

\section{Spheroid formation}

At recovery day 7 after paclitaxel treatment, PGCCs were dissociated and cultured with FBS-free stem cell medium (Gibco, Grand island, NY, USA) in low-attachment plates (Corning, Corning, NY, USA). A total of 5000 test cells in $3 \mathrm{ml}$ of stem cell medium were cultured in $60 \mathrm{~mm}$ low-attachment dishes. Spheroid formation was then observed for an additional 14 days. Spheroids more than $100 \mu \mathrm{m}$ in diameter were counted. Spheroids were 

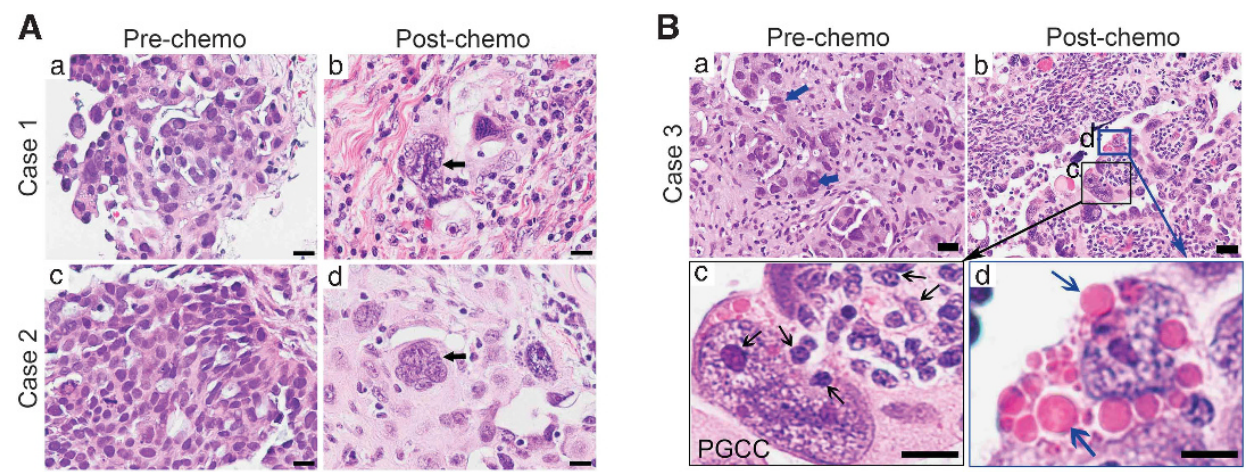

C

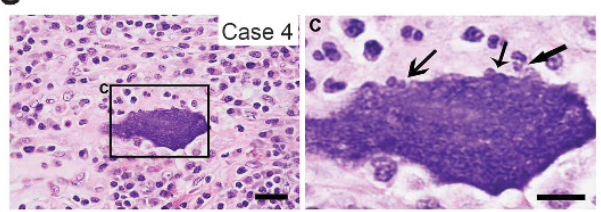

D
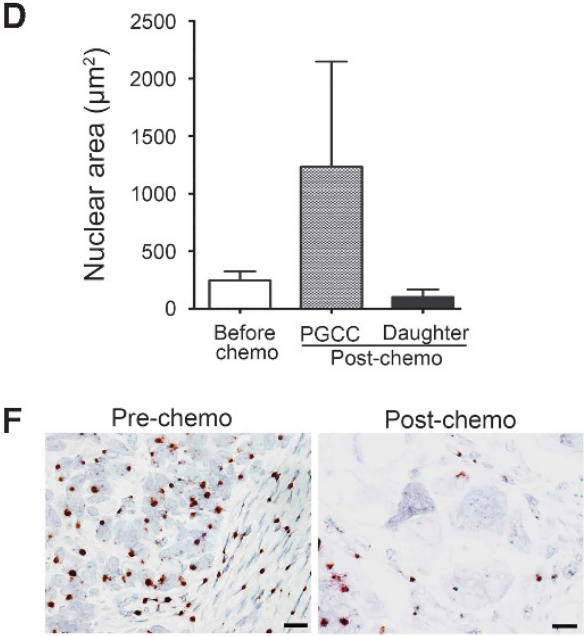

E

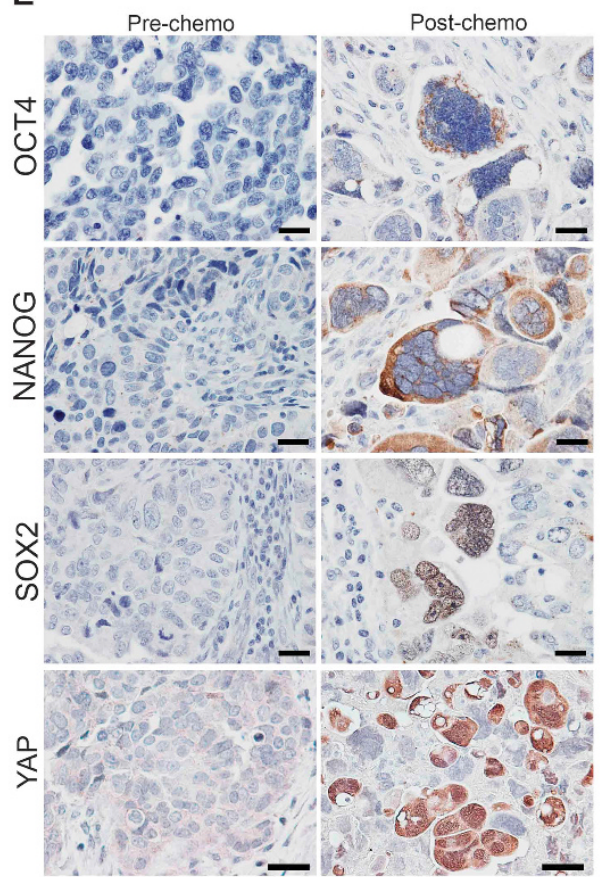

Figure 7. PGCCs and differentiation in ovarian cancer specimens. (a-c) Hematoxylin-eosin (H\&E) staining shows the PGCC populations before and after chemotherapy in three paired cases. In the first two cases (A), cells in the pre-chemotherapy specimen were homogeneous in size and morphology with small round nuclei; the PGCCs (black arrows) present after chemotherapy had large bizarre nuclei and rich cytoplasm. In the third case (B), some large cancer cells were present before chemotherapy (a; blue arrows), but PGCCs present after chemotherapy (b) were larger. Some small daughter cells (black arrows) budded off from the PGCCs (c, higher magnification of b) and some erythrocyte-like vacuoles formed in the cytoplasm of PGCCs (d, higher magnification of b) and released out (blue arrows). In case 4 (C), there was prominent budding from PGCCs after chemotherapy (indicated by black arrows). (D) Nuclear area of cancer cells before chemotherapy and PGCCs and daughter cells after chemotherapy. (E) Expression of OCT4, NANOG, SOX2 and YAP in cancer cells before chemotherapy and PGCCs after chemotherapy. (F) RNA in situ hybridization analysis of Xist. Before chemotherapy, Xist was widely positive in most nuclei of cancer cells and stromal cells; after chemotherapy, there were fewer positive spots in the nuclei of PGCCs.

also grown from PGCCs induced by $\mathrm{CoCl}_{2}$ as previously described; ${ }^{2}$ these spheroids were used to study endoderm differentiation.

Hematoxylin-eosin staining, immunohistochemistry and immunofluorescence

Hematoxylin-eosin staining, IHC and single and double immunofluorescence labeling were performed as described previously ${ }^{2}$. Primary antibodies are listed in Supplementary Table 1.

$\beta$-Gal staining

$\beta$-Gal staining for senescence was performed as described previously. ${ }^{67}$

Western blot analysis

Western blot analysis was performed as described previously. ${ }^{68}$
Scanning electron microscopy

Attached PGCCs, spheroids and control regular cancer cells were examined with scanning electron microscopy as previously described. ${ }^{69}$

Live 3D confocal scanning of early-stage PGCC-derived spheroids GFP-ubiquitin-labeled Hey cells were treated with paclitaxel, allowed to recover in regular medium for 7 days, and then cultured with stem cell medium for 2 days. The cells and spheroids were stained with Hoechst 33342 and multiply scanned at $X Y$ axis along the $Z$ direction; images were reconstructed with a Carl Zeiss 710 confocal microscope (Zeiss, Thornwood, NY, USA).

Xist RNA in situ hybridization

An RNAscope immunofluorescence kit (Advanced Cell Diagnostics, Hayward, CA, USA) was used on fixed cells on coverslips and an RNAscope 


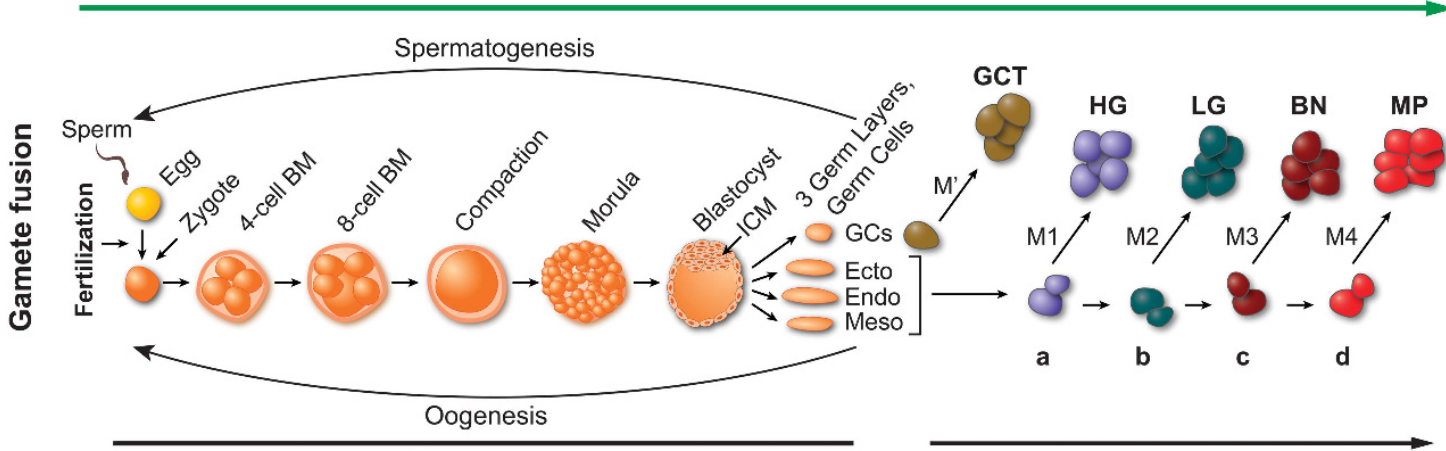

Preimplantation

Pierce Maturation Arrest

b

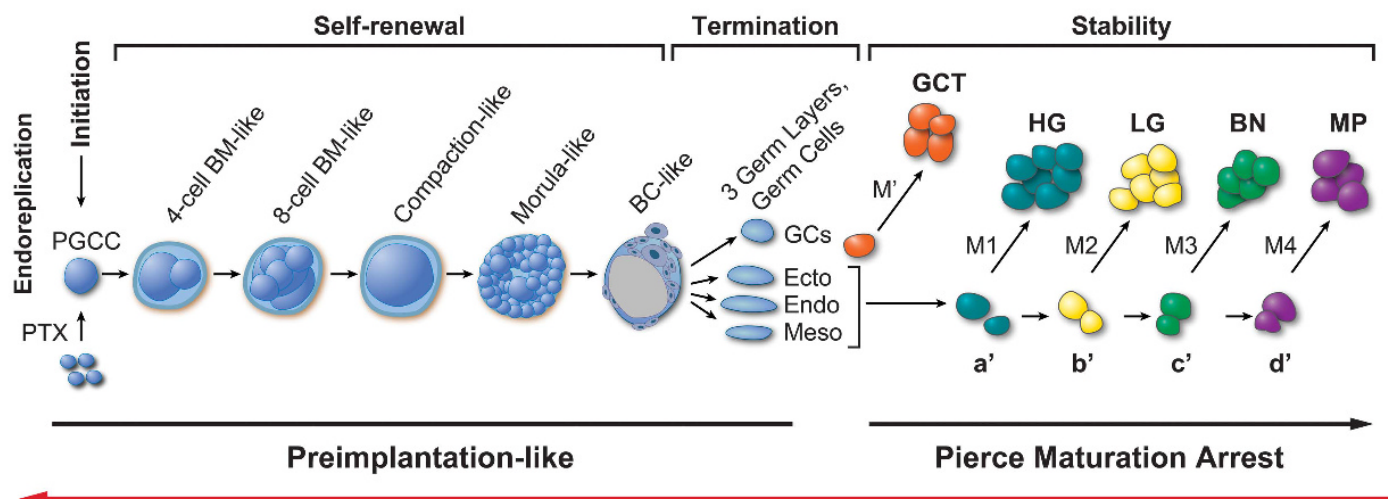

Reprogramming / Dedifferentiation

Figure 8. Schematic of blastomere model for cancer origin and disease relapse. (A) Blastomere-mediated embryogenesis during differentiation (normal development) and subsequent tumor formation associated with maturation arrest of stem cells in different organs during adulthood. Following gamete fusion (sex), zygote will develop into blastomeres, compaction, morula and blastocyst/ICM. Inner cell mass will develop into primordial germ cells, which will proceed with spermatogenesis (male) or oogenesis (female); while three germ layers will develop into somatic tissues containing stem cells of primitive multipotency (a), intermediate potency (b) or late oligo-potency (c) or mature stable cells (d). Maturation arrest at different developmental hierarchies leads to formation of germ cell tumors (GCTs) or germ-layerspecific tumor with different grades of malignancy: high-grade tumors (HG), low-grade tumors (LG), benign tumors (BN) or metaplasia (MP). BM, blastomere; Endo, endoderm; Ecto, ectoderm; Meso, mesoderm; GCs, germ cells; ICM, inner cell mass. M' and M represent different genetic/epigenetic mutations acquired in germ cells and somatic cells respectively during embryonic or in adult development. a, b, $c$, and $d$ represent different levels of hierarchy in normal development. (B) Induced blastomere-like-mediated oncogenesis via dedifferentiation (reprogramming) of somatic cells. Following mitotic failure induced by paclitaxel (PTX), somatic cells initiate endoreplication to generate PGCCs, which grow into blastomere-like (BM-like), compaction-like and morula-like cell masses (self-renewal) and then differentiate into structures morphologically similar to the blastocyst with inner cell mass and then into the three germ layers and germ cell lineage (termination). The entire process mimics development of preimplantation embryo via the giant cell cycle (preimplantation-like). The germ cells and primitive stem cells arrest at different developmental hierarchies to generate germ cell tumors (GCTs) and somatic tumors with different levels of malignancy. $a^{\prime}, b^{\prime}, c^{\prime}$ and $d^{\prime}$ correspond to levels of developmental hierarchy following stress-induced reprogramming.

kit (Advanced Cell Diagnostics) on sections of human ovarian cancer according to the manufacturer's protocol.

Analysis of stemness and differentiation capacity of PGCCs

PGCCs were cultured with stem cell medium for 7 days, reattached on coverslips and cultured on Matrigel (Corning)-coated coverslips with specific differentiation media (Gibco: adipogenesis, chondrogenesis and osteogenesis differentiation media; Stem Cell Technologies (Cambridge, MA, USA): endoderm differentiation, astrocyte-inducing, differentiation and mature media) according to the manufacturers' protocols. Dobutamine $(10 \mu \mathrm{m})$ was used to block the nuclear accumulation of YAP. The cells were then fixed with $10 \%$ paraformaldehyde/PBS for immunofluorescence staining.

Oil red staining for fat vacuoles was performed with a lipid staining kit (Zenbio, Research Triangle Park, NC, USA) and Alcian blue staining for chondroitin was performed with an Alcian blue $\mathrm{pH} 2.5$ periodic acid-Schiff staining kit (Fisher Scientific, New Kensington, PA, USA) according to the manufacturer's protocol. Immunofluorescence staining against osteogenin, AFP, CXCR4, c-Kit, YAP, GFAP, CD133, SMA and $\beta 3$-tubulin was performed as described previously. ${ }^{70}$ Primary antibodies are listed in Supplementary Table 1.
Flow cytometry

ALDH1-FITC, CD133-PE and CD117-APC were incubated with Hey-derived PGCCs at recovery day 7 (sD1) and analyzed by a FACS Canto II flow cytometer (BD Biosciences, San Jose, CA, USA). The ovarian cancer cells stained with propidium iodide (Sigma) were also analyzed by a FACS Canto II flow cytometer.

Invasion analysis and 3D culture

Invasion assay was performed in a matrigel invasion chamber (BD Biosciences, Bedford, MA, USA) according to the manufacturer's protocol. The 3D spatial structure of control and PGCC-derived spheroids was determined with an Alvetex scaffold system (AMS Biotechnology, Cambridge, MA, USA) according to the manufacturer's protocol.

Reverse transcription and real-time quantitative PCR

Total RNA from PGCCs at different time points (days 1, 3, 7, 14, 21, 28) was extracted and purified using an RNeasy Kit (Qiagen, Dusseldorf, Germany); $1 \mu \mathrm{g}$ of total RNA was used for reverse transcription with Iscript Reverse Transcription Supermix (Bio-Rad, Hercules, CA, USA), and qPCR reactions were performed in 
triplicate as described previously. ${ }^{70}$ The primers for OCT4, NANOG, DAZL, AFP, SMA and PAX6 were designed as described previously. ${ }^{71,72}$ Changes in gene expression were calculated by using the $\Delta \Delta \mathrm{Ct}$ method.

Tumorigenesis in mice from spheroids or daughter cells derived from single PGCCs

Spheroids derived from single PGCCs and control cells were cultured in stem cell medium for 7 days. For testis injection, single spheroids in $10 \mu l$ of PBS were injected one spheroid per mouse into the testis of male SCID mice 2 months of age (16 injections) and controls (eight mice). Daughter cells from single PGCC-derived colonies were isolated and passaged for more than 10 generations to obtain stable populations. Then $10^{4}$ daughter or control cancer cells in $50 \mu \mathrm{l}$ of PBS and $50 \mu \mathrm{l}$ of Matrigel (Corning) were injected subcutaneously into the SCID mice. When tumors reached $1 \mathrm{~cm}$, the mice were killed, and the tumor nodules were harvested for histology and IHC. Tumor types were diagnosed by two pathologists (JL and NN). The primary antibodies are listed in Supplementary Table 1. The use and care of mice were approved by the MD Anderson's Institutional Animal Care and Use Committee.

\section{Statistics}

The number and diameter of spheroids were assessed in randomly selected fields by light microscopy $(\times 4)$ and analyzed with $t$-test or oneway analysis of variance. Relative folds of IC50 of tested drugs, diagnosis and differentiation of xenografts were analyzed with $x^{2}$ test. Significance was defined as $P<0.05$, and all tests were two-sided. Statistical tests were performed with SPSS software (SPSS for Windows version 22.0, SPSS Inc, Chicago, IL, USA). All quantitative results were presented as mean \pm s.d.

\section{CONFLICT OF INTEREST}

The authors declare no conflict of interest.

\section{ACKNOWLEDGEMENTS}

This work was supported in part by a multi-investigator grant from the Cancer Prevention and Research Institute of Texas (JL); a Sister Institution Grant from MD Anderson Cancer Center Global Academic Programs; and National Cancer Institute Cancer Center Support Grant CA016672, which supported the High Resolution Electron Microscopy Facility. We thank Kim Vu for image artwork and Stephanie Deming for editorial assistance. We thank many colleagues for helpful discussions. We apologize for many investigators who embraced embryonic origin of tumor or its variants over past two centuries whose work can not be cited and discussed due to space limitation.

\section{REFERENCES}

1 Kumar V, Abbas AK, Fausto N, Aster J. Neoplasia. Robbins and Cotran Pathologic Basis of Disease. Sauders Elsevier: Philadelphia, PA, USA, 2010; Chapter 7, pp 262-270.

2 Zhang S, Mercado-Uribe I, Xing Z, Sun B, Kuang J, Liu J. Generation of cancer stem-like cells through the formation of polyploid giant cancer cells. Oncogene 2014; 33: 116-128.

3 Zack TI, Schumacher SE, Carter SL, Cherniack AD, Saksena G, Tabak B et al. Pan-cancer patterns of somatic copy number alteration. Nat Genet 2013; 45: 1134-1140.

4 Ganem NJ, Pellman D. Limiting the proliferation of polyploid cells. Cell 2007; 131 437-440.

5 Munoz-Espin D, Serrano M. Cellular senescence: from physiology to pathology. Nat Rev Mol Cell Biol 2014; 15: 482-496.

6 Ewald JA, Desotelle JA, Wilding G, Jarrard DF. Therapy-induced senescence in cancer. J Natl Cancer Inst 2010; 102: 1536-1546.

7 Campisi J. Aging, cellular senescence, and cancer. Annu Rev Physiol 2013; 75: 685-705.

8 Erenpreisa J, Kalejs M, lanzini F, Kosmacek EA, Mackey MA, Emzinsh D et al. Segregation of genomes in polyploid tumour cells following mitotic catastrophe. Cell Biol Int 2005; 29: 1005-1011.

9 Erenpreisa JA, Cragg MS, Fringes B, Sharakhov I, Illidge TM. Release of mitotic descendants by giant cells from irradiated Burkitt's lymphoma cell line. Cell Biol Int 2000; 24: 635-648.
10 Sundaram M, Guernsey DL, Rajaraman MM, Rajaraman R. Neosis: a novel type of cell division in cancer. Cancer Biol Ther 2004; 3: 207-218.

11 Walen $\mathrm{KH}$. Budded karyoplasts from multinucleated fibroblast cells contain centrosomes and change their morphology to mitotic cells. Cell Biol Int 2005; 29: 1057-1065.

12 Puig PE, Guilly MN, Bouchot A, Droin N, Cathelin D, Bouyer F et al. Tumor cells can escape DNA-damaging cisplatin through DNA endoreduplication and reversible polyploidy. Cell Biol Int 2008; 32: 1031-1043.

13 Leikam C, Hufnagel AL, Otto C, Murphy DJ, Muhling B, Kneitz S et al. In vitro evidence for senescent multinucleated melanocytes as a source for tumorinitiating cells. Cell Death Dis 2015; 6: e1711.

14 Zhang S, Mercado-Uribe I, Sood A, Bast RC, Liu J. Coevolution of neoplastic epithelial cells and multilineage stroma via polyploid giant cells during immortalization and transformation of mullerian epithelial cells. Genes Cancer 2016; 7: 60-72

15 Weihua Z, Lin Q, Ramoth AJ, Fan D, Fidler IJ. Formation of solid tumors by a single multinucleated cancer cell. Cancer 2011; 117: 4092-4099.

16 Fujiwara T, Bandi M, Nitta M, Ivanova EV, Bronson RT, Pellman D. Cytokinesis failure generating tetraploids promotes tumorigenesis in p53-null cells. Nature 2005; 437: 1043-1047.

17 Davoli T, de Lange T. Telomere-driven tetraploidization occurs in human cells undergoing crisis and promotes transformation of mouse cells. Cancer Cell 2012; 21: 765-776.

18 Wang Q, Wu PC, Dong DZ, Ivanova I, Chu E, Zeliadt S et al. Polyploidy road to therapy-induced cellular senescence and escape. Int J Cancer 2013; 132: 1505-1515.

19 Mosieniak G, Sliwinska MA, Alster O, Strzeszewska A, Sunderland P, Piechota M et al. Polyploidy formation in doxorubicin-treated cancer cells can favor escape from senescence. Neoplasia 2015; 17: 882-893.

20 Chakradeo S, Elmore LW, Gewirtz DA. Is senescence reversible? Curr Drug Targets 2015; 17: 460-466.

21 Zhang S, Mercado-Uribe I, Liu J. Generation of erythroid cells from fibroblasts and cancer cells in vitro and in vivo. Cancer Lett 2013; 333: 205-212.

22 Zhang S, Mercado-Uribe I, Liu J. Tumor stroma and differentiated cancer cells can be originated directly from polyploid giant cancer cells induced by paclitaxel. Int $J$ Cancer 2013; 134: 508-518.

23 Lopez-Sanchez LM, Jimenez C, Valverde A, Hernandez V, Penarando J, Martinez A et al. $\mathrm{CoCl} 2$, a mimic of hypoxia, induces formation of polyploid giant cells with stem characteristics in colon cancer. PLoS One 2014; 9: e99143.

24 Braune EB, Tsoi YL, Phoon YP, Landor S, Silva Cascales H, Ramskold D et al. Loss of CSL unlocks a hypoxic response and enhanced tumor growth potential in breast cancer cells. Stem Cell Rep 2016; 6: 643-651.

25 Niu N, Zhang J, Zhang N, Mercado-Uribe I, Tao F, Han Z et al. Linking genomic reorganization to tumor initiation via the giant cell cycle. Oncogenesis 2016; 5: e281.

26 Zielke N, Edgar BA, DePamphilis ML. Endoreplication. Cold Spring Harb Perspect Biol 2013; 5: a012948.

27 Fox DT, Duronio RJ. Endoreplication and polyploidy: insights into development and disease. Development 2013; 140: 3-12.

28 Athayde Wirka K, Chen AA, Conaghan J, Ivani K, Gvakharia M, Behr B et al. Atypical embryo phenotypes identified by time-lapse microscopy: high prevalence and association with embryo development. Fertil Steril 2014; 101: 1637-1648.e1-5.

29 Chavez SL, Loewke KE, Han J, Moussavi F, Colls P, Munne S et al. Dynamic blastomere behaviour reflects human embryo ploidy by the four-cell stage. Nat Commun 2012; 3: 1251.

30 Hardy K, Winston RM, Handyside AH. Binucleate blastomeres in preimplantation human embryos in vitro: failure of cytokinesis during early cleavage. J Reprod Fertil 1993; 98: 549-558.

31 Kligman I, Benadiva C, Alikani M, Munne S. The presence of multinucleated blastomeres in human embryos is correlated with chromosomal abnormalities. Hum Reprod 1996; 11: 1492-1498.

32 Van Royen E, Mangelschots K, Vercruyssen M, De Neubourg D, Valkenburg M, Ryckaert $\mathrm{G}$ et al. Multinucleation in cleavage stage embryos. Hum Reprod 2003: 18: $1062-1069$.

33 Benkhalifa M, Janny L, Vye $\mathrm{P}$, Malet $\mathrm{P}$, Boucher D, Menezo Y. Assessment of polyploidy in human morulae and blastocysts using co-culture and fluorescent in situ hybridization. Hum Reprod 1993; 8: 895-902.

34 Vanneste E, Voet T, Le Caignec C, Ampe M, Konings P, Melotte C et al. Chromosome instability is common in human cleavage-stage embryos. Nat Med 2009; 15 : 577-583.

35 Mertzanidou A, Wilton L, Cheng J, Spits C, Vanneste E, Moreau Y et al. Microarray analysis reveals abnormal chromosomal complements in over $70 \%$ of 14 normally developing human embryos. Hum Reprod 2013; 28: 256-264.

36 Ledbetter DH. Chaos in the embryo. Nat Med 2009; 15: 490-491. 
37 Iwata K, Yumoto K, Sugishima M, Mizoguchi C, Kai Y, Iba Y et al. Analysis of compaction initiation in human embryos by using time-lapse cinematography. J Assist Reprod Genet 2014; 31: 421-426.

38 Sadler T. Langman's Medical Embryology, 12th edn. Lippincott Willians \& Wilkins: Philadelphia, PA, USA, 2012.

39 Gasser RF. The Virtual Human Embryo, Carnegie Stage 2 Figures. Available at: https://www.ehd.org/virtual-human-embryo/figures.php?stage $=2$.

40 Rohwedel J, Guan K, Wobus AM. Induction of cellular differentiation by retinoic acid in vitro. Cells, tissues, organs 1999; 165: 190-202.

41 Wutz A. Xist function: bridging chromatin and stem cells. Trends Genet 2007; 23: 457-464.

42 Chen HH, Welling M, Bloch DB, Munoz J, Mientjes E, Chen X et al. DAZL limits pluripotency, differentiation, and apoptosis in developing primordial germ cells. Stem Cell Rep 2014; 3: 892-904.

43 Kurman RJ, Shih le M. The dualistic model of ovarian carcinogenesis: revisited, revised, and expanded. Am J Pathol 2016; 186: 733-747.

44 Yu FX, Zhao B, Guan KL. Hippo pathway in organ size control, tissue homeostasis, and cancer. Cell 2015; 163: 811-828.

45 Ganem NJ, Cornils H, Chiu SY, O'Rourke KP, Arnaud J, Yimlamai D et al. Cytokinesis failure triggers hippo tumor suppressor pathway activation. Cell 2014; 158: 833-848.

46 Schrode N, Saiz N, Di Talia S, Hadjantonakis AK. GATA6 levels modulate primitive endoderm cell fate choice and timing in the mouse blastocyst. Dev Cell 2014; 29: 454-467.

47 Pierce GB. Teratocarcinoma: model for a developmental concept of cancer. Curr Top Dev Biol 1967; 2: 223-246.

48 Andrews PW. From teratocarcinomas to embryonic stem cells. Philos Trans $R$ Soc Lond B Biol Sci 2002; 357: 405-417.

49 Cohnheim J. Ueber entzundung und eiterung. Pathol Anat Klin Med 1867; 40: $1-79$.

50 Stevens LC, Little CC. Spontaneous testicular teratomas in an inbred strain of mice. Proc Natl Acad Sci USA 1954; 40: 1080-1087.

51 Stevens LC. Experimental production of testicular teratomas in mice. Proc Natl Acad Sci USA 1964; 52: 654-661.

52 Kleinsmith $\sqcup$, Pierce GB Jr. Multipotentiality of single embryonal carcinoma cells. Cancer Res 1964; 24: 1544-1551.

53 Pierce GB, Wallace C. Differentiation of malignant to benign cells. Cancer Res 1971; 31: 127-134.

54 Pierce GB, Speers WC. Tumors as caricatures of the process of tissue renewal: prospects for therapy by directing differentiation. Cancer Res 1988; 48: 1996-2004.

55 Pierce GB. The cancer cell and its control by the embryo. Rous-Whipple Award lecture. Am J Pathol 1983; 113: 117-124.

56 Gurdon JB, Elsdale TR, Fischberg M. Sexually mature individuals of Xenopus laevis from the transplantation of single somatic nuclei. Nature 1958; 182: 64-65.

57 Takahashi K, Yamanaka S. Induction of pluripotent stem cells from mouse embryonic and adult fibroblast cultures by defined factors. Cell 2006; 126: 663-676.

58 Wilmut I, Schnieke AE, McWhir J, Kind AJ, Campbell KH. Viable offspring derived from fetal and adult mammalian cells. Nature 1997; 385: 810-813.

59 Blum B, Benvenisty N. The tumorigenicity of human embryonic stem cells. Adv Cancer Res 2008; 100: 133-158.
60 Lee AS, Tang C, Rao MS, Weissman IL, Wu JC. Tumorigenicity as a clinical hurdle for pluripotent stem cell therapies. Nat Med 2013; 19: 998-1004.

61 Ohnishi K, Semi K, Yamamoto T, Shimizu M, Tanaka A, Mitsunaga K et al. Premature termination of reprogramming in vivo leads to cancer development through altered epigenetic regulation. Cell 2014; 156: 663-677.

62 Salmina K, Jankevics E, Huna A, Perminov D, Radovica I, Klymenko T et al. Upregulation of the embryonic self-renewal network through reversible polyploidy in irradiated p53-mutant tumour cells. Exp Cell Res 2010; 13: 2099-2112.

63 Schiff PB, Fant J, Horwitz SB. Promotion of microtubule assembly in vitro by taxol. Nature 1979; 277: 665-667.

64 Weaver BA, Cleveland DW. Decoding the links between mitosis, cancer, and chemotherapy: the mitotic checkpoint, adaptation, and cell death. Cancer Cell 2005; 8: 7-12.

65 Zasadil LM, Andersen KA, Yeum D, Rocque GB, Wilke LG, Tevaarwerk AJ et al. Cytotoxicity of paclitaxel in breast cancer is due to chromosome missegregation on multipolar spindles. Sci Trans Med 2014; 6: 229 ra43.

66 Ogden A, Rida PC, Knudsen BS, Kucuk O, Aneja R. Docetaxel-induced polyploidization may underlie chemoresistance and disease relapse. Cancer Lett 2015; 367: 89-92.

67 Yang G, Rosen DG, Zhang Z, Bast Jr RC, Mills GB, Colacino JA et al. The chemokine growth-regulated oncogene 1 (Gro-1) links RAS signaling to the senescence of stromal fibroblasts and ovarian tumorigenesis. Proc Natl Acad Sci USA 2006; 103: 16472-16477.

68 Liu G, Yang G, Chang B, Mercado-Uribe I, Huang M, Zheng J et al. Stanniocalcin 1 and ovarian tumorigenesis. J Natl Cancer Inst 2010; 102: 812-827.

69 Szajnik M, Derbis M, Lach M, Patalas P, Michalak M, Drzewiecka H et al. Exosomes in plasma of patients with ovarian carcinoma: potential biomarkers of tumor progression and response to therapy. Gynecol Obstet (Sunnyvale) 2013; Suppl 4: 3.

70 Niu N, Zhang J, Sun Y, Wang S, Sun Y, Korteweg C et al. Expression and distribution of immunoglobulin $\mathrm{G}$ and its receptors in an immune privileged site: the eye. Cell Mol Life Sci 2011; 68: 2481-2492.

71 Kamiyama T, Takahashi M, Nakagawa T, Nakanishi K, Kamachi H, Suzuki T et al. AFP mRNA detected in bone marrow by real-time quantitative RT-PCR analysis predicts survival and recurrence after curative hepatectomy for hepatocellular carcinoma. Ann Surg 2006; 244: 451-463.

72 Forsdahl S, Kiselev Y, Hogseth R, Mjelle JE, Mikkola I. Pax6 regulates the expression of Dkk3 in murine and human cell lines, and altered responses to Wnt signaling are shown in FIpln-3T3 cells stably expressing either the Pax6 or the Pax6(5a) isoform. PLoS One 2014; 9: e102559.

(c) (1) This work is licensed under a Creative Commons Attributioncc. No NC SA Nommercial-ShareAlike 4.0 International License. The images or other third party material in this article are included in the article's Creative Commons license, unless indicated otherwise in the credit line; if the material is not included under the Creative Commons license, users will need to obtain permission from the license holder to reproduce the material. To view a copy of this license, visit http:// creativecommons.org/licenses/by-nc-sa/4.0/

(c) The Author(s) 2017

Supplementary Information accompanies this paper on the Oncogene website (http://www.nature.com/onc) 